\title{
Inequality in People's Minds
}

L. Taylor Phillips ${ }^{1, *}$, Stephanie J. Tepper ${ }^{2, \approx}$, Daniela Goya-Tocchetto ${ }^{3, \approx}$, Shai Davidai ${ }^{4,(\mathbb{P}}$,

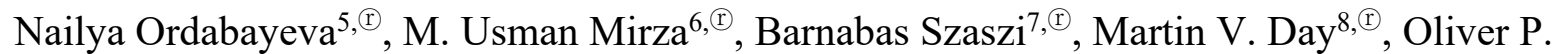
Hauser $^{*}, 9$, \& Jon M. Jachimowicz ${ }^{*}, 10$

\footnotetext{
${ }^{1}$ New York University, Stern School of Business; ${ }^{2}$ Cornell University, Department of Psychology; ${ }^{3}$ Duke University, Fuqua School of Business; ${ }^{4}$ Columbia University, Columbia Business School; ${ }^{5}$ Boston College, Carroll School of Management; ${ }^{6}$ Maastricht University, School of Business and Economics; ${ }^{7}$ Eotvos Loránd University; ${ }^{8}$ Memorial University of Newfoundland; $;{ }^{9}$ University of Exeter Business School; ${ }^{10}$ Harvard University, Harvard Business School
}

*To whom correspondence should be addressed: 1taylorphillips@stern.nyu.edu; o.hauser@exeter.ac.uk; jjachimowicz@hbs.edu.

\section{Author Notes}

This paper emerged from a workshop on perceptions of economic inequality organized by Oliver P. Hauser and Jon M. Jachimowicz, and funded by the Tobin Foundation, the International Association for Research in Economic Psychology (IAREP), and the Department of Economics at the University of Exeter Business School. Authors denoted by $\approx$ (Stephanie J. Tepper and Daniela Goya-Tocchetto) share second authorship; their order was determined by a coin flip. The author order of Shai Davidai, Nailya Ordabayeva, M. Usman Mirza, Barnabas Szaszi, and Martin V. Day was randomized using the AER Author Randomization Tool (https://www.aeaweb.org/journals/policies/randomauthor-order/generator), Confirmation Code: FDcCaKcbW6BH. 


\begin{abstract}
The perceived extent of inequality often better predicts individual policy preferences and political action than does the actual extent of inequality. Scholars across the social sciences are working to understand individuals' (mis)perceptions of inequality. However, this work predominantly focuses on people's numeric estimates of inequality, paying less attention to how people form these perceptions or what they mean to participants. We draw on perception, cognition, developmental, and social psychology to introduce a comprehensive framework, suggesting that perceptions of inequality should be viewed as a process that unfolds across five interlinked, iterative components. When forming perceptions of the scope of inequality in society, people (1) access inequality cues in the world, (2) attend to these cues, (3) comprehend these cues, (4) process these cues in a motivated manner, and (5) summarize these cues into a meaningful representation of inequality. These components are subject to motivational or cognitive biases and can unfold linearly or nonlinearly (i.e., concurrently, in different orders, or repeatedly over time). Our framework outlines the building blocks of people's perceptions of economic inequality, and provides a roadmap to examine how people's perceptual processes affect their understanding and actions regarding inequality.
\end{abstract}

Keywords: economic inequality; inequality cues; folk economics; social class; lay beliefs; perception 
Economic inequality is associated with a wide range of adverse outcomes at the individual, group, and societal levels. For example, areas with higher inequality tend to have higher levels of school bullying, worse mental and physical health, and lower perceived social mobility (Elgar et al., 2019; Pickett \& Wilkinson, 2015; see also Buttrick \& Oishi, 2017). Thus, one may expect people to increasingly rebel against rising levels of economic inequality (Meltzer \& Richard, 1981). However, given the magnitude and trajectory of inequality, people do not seem to be nearly as troubled about the high (and in some cases rising) levels in many countries around the world as one might expect them to be (Kuziemko et al., 2015; Peyton, 2020). For example, policies to redistribute economic resources often garner limited support (Bartels, 2005; Bechtel, Liesch, \& Scheve, 2018).

One reason for this is that people's perceptions of the level of inequality in society do not match the reality around them (Norton \& Ariely, 2011; Hauser \& Norton, 2017). There is a growing consensus among researchers that instead of acting based on objective indicators of economic inequality, people - even children - act based on their subjective perceptions of its scope (Elenbaas, 2019; Franko, 2017; García-Castro et al., 2020; García-Sánchez et al., 2019; Kim, Pedersen, \& Mutz, 2016; Kuhn, 2019; Niehues, 2014; Norton, 2014; SánchezRodríguez et al., 2019; Trump, 2020). In other words, lay perceptions of inequality are believed to be a critical piece of the puzzle, clarifying when and why people seem to tolerate high levels of inequality. At the same time, although prior research broadly agrees that people tend to misestimate the true levels of inequality in society (Gimpelson \& Treisman, 2018; Hauser \& Norton, 2017), it is less clear how lay perceptions of inequality are formed and why they so often differ from reality. As a result, researchers often draw conclusions about the effects of people's perceptions of inequality without fully understanding where these perceptions come from and what they mean. 
Here, we propose a theoretical framework for understanding these lay perceptions. We conceptualize perceptions of inequality as process, formed dynamically by five iterative and interlinked subprocesses. Drawing on research in perception, cognition, developmental, and social psychology, we detail how people access, attend to, comprehend, motivatedly process, and meaningfully summarize the cues of inequality in their environment, and how these components are shaped by a variety of biases. In turn, we suggest that this perceptual process (and its relative lack of acknowledgment in inequality scholars' current approaches) may elucidate why perceptions of inequality often do not reflect reality.

\section{Overview and Scope}

We aim to provide a theoretical grounding regarding the construct "perceptions" as it applies to perceptions of economic inequality. ${ }^{1} \mathrm{We}$ propose that approaching perceptions of inequality with more conceptual clarity, rooted in the psychological process of perceiving (i.e., how people access, attend to, comprehend, motivatedly process, and meaningfully summarize inequality cues), will shed much-needed light on these perceptions, including when, how, and why they affect people's beliefs and behaviors.

The rest of the paper is organized as follows. First, we briefly review research on perceptions of economic inequality, summarizing existing approaches and highlighting what each method can offer to researchers. From this review, we extract several implied definitions of perceptions of inequality and identify sources of confusion and imprecision, which highlight the need for a clearer conceptualization of this construct. Next, we provide a conceptual framework to better understand perceptions of economic inequality by treating perception as a process, rather than an output, and unpacking its components. Finally,

\footnotetext{
${ }^{1}$ Throughout this paper, we use the term "inequality" to refer to economic inequality (inequality of wealth, income, and other economic resources) and the ways it intersects with demographic characteristics, such as race and gender. Nevertheless, just as the term "perceptions" has been treated without much clarity in prior work, "inequality" has also been defined in myriad ways and would benefit from more conceptual clarification (for discussion, see Jachimowicz, Davidai et al., 2020).
} 
following this framework, we consider how treating perceptions of inequality as a process shapes the questions researchers may ask and the methods they ought to consider using in their research. In particular, we consider what new questions are surfaced by this process approach to perceptions of inequality, and how our conceptual framework might help researchers choose more precise methodological approaches to answer them.

\section{What Are "Perceptions" of Inequality? Overview of Current Approaches}

One of the most influential ideas across the social sciences is that people are often as affected by their subjective perceptions of the world as they are by its objective conditions (Goffman, 1974; Gramsci, 1971; Wertheimer, 1938). Consequently, because subjective perceptions of economic inequality may not accurately reflect the actual state of world, the historic rise of inequality in some countries does not seem to translate to a similar rise in support for redistribution of public goods (Engelhardt \& Wagener, 2014; Hauser \& Norton, 2017; Niehues, 2014; Son Hing et al., 2019). Indeed, despite the rise in economic inequality in the U.S. and other OECD nations over recent decades, support for redistributive action in these countries may even have declined (Ashok, Kuziemko, \& Washington, 2015; Kenworthy \& McCall, 2008; Kuziemko et al., 2015).

The idea that perceptions of economic inequality are the missing link between the actual distributions of resources in society and people's policy preferences has received growing interest. Even when the actual levels of economic inequality are high, individual action requires an adequate estimation of this dispersion (Acemoglu \& Robinson, 2006; Guinjoan \& Rico, 2018; Hauser \& Norton, 2017; Osberg \& Smeeding, 2006). Norton and Ariely (2011) sparked renewed interest in this perspective, suggesting that individualsacross political and income divides - underestimate the degree to which wealth is distributed unequally and generally prefer a more equal distribution of wealth than the status quo. Thus, 
one reason why people may not take action to redress economic inequality is rooted in their misperceptions of its true extent.

In the years since Norton and Ariely (2011), researchers across the social sciences have developed various methods to elicit perceptions of economic inequality. However, consensus regarding which method is most appropriate for measuring perceptions of inequality (and why) is lacking. Depending on how people's perceptions are elicited, some methods have demonstrated substantial underestimation of economic inequality (e.g., Hoy, Toth, \& Merdikawati, 2019; Kiatpongsan \& Norton, 2014; Kraus, Rucker, \& Richeson, 2017; Niehues, 2014; Norton \& Ariely, 2013), while other methods have demonstrated substantial overestimation of it (e.g., Chambers, Swan, \& Heesacker, 2014; Eriksson \& Simpson, 2012). As more methods continue to be developed, the range of options for measuring perceptions of inequality expands at the expense of clarity regarding their appropriateness. This has produced a field excited but muddled by the variety and potential of methodological approaches, which often reach different conclusions to similar research questions.

We suggest that different methods imply different interpretations of what "perception" means, that is, how different researchers are conceptualizing this construct. Over time, variance in these implied conceptualizations may contribute to confusion and imprecision in understanding lay perceptions of economic inequality. To illustrate, we briefly consider three exemplar methods (for a comprehensive review focused on measurement, see Knell \& Stix, 2020).

\section{Current Approaches}

One method of eliciting perceptions of inequality asks people to provide numerical estimates of how economic resources (e.g., household wealth) are distributed across several distributional categories (or “buckets”). For example, Norton and Ariely (2011) presented participants with a definition of wealth and asked them what percentage of wealth was held 
by each quintile in the United States, starting with the top $20 \%$ and ending with the bottom $20 \%$. The authors compared these estimates to the actual distribution of wealth across quintiles, revealing that participants significantly underestimated wealth inequality, believing that the top quintile held $59 \%$ (rather than the actual $84 \%$ ) of the total wealth.

Overall, this approach focuses on eliciting people's numerical estimates of the distribution of resources in society. Several variations of this approach have proliferated, asking participants to graphically manipulate a histogram (e.g., Page \& Goldstein, 2016), assess the average income of distributional groups (e.g., Eriksson \& Simpson, 2012), or evaluate their own position within the distribution (e.g., Engelhardt \& Wagener, 2014). While these variations launched generative debates among scholars regarding perceptions of inequality, we believe that they are strikingly similar in their implied definitions of "perceptions." Specifically, despite variations in the measures, these approaches are similar in operationalizing perceptions as a numeric, distributional representation of inequality. As such, they imply that lay people think in terms of numeric distributions - an important, yet untested, assumption.

A second category of methodological approaches for eliciting perceptions of inequality asks individuals to provide numerical estimates of how much specific exemplars in society have relative to one another. For instance, Kraus, Rucker, et al. (2017) probed participants' perceptions of racial wealth inequality by asking them to estimate how much wealth is owned by an average Black family for every $\$ 100$ owned by an average White family. The authors found that participants greatly underestimated the level of racial wealth inequality, believing that Black families own significantly more wealth than they do in reality.

Overall, this approach operationalizes perceptions of inequality as a comparative process, allowing participants to think in terms of categorical exemplars (e.g., the average 
Black family) and explicitly compare the economic resources between such exemplars. Variations on this approach have considered other exemplar categories, including other social groups (e.g., Asian Americans; Kuo et al., 2020) and job roles (e.g., a CEO, a cabinet minister, and an unskilled factory worker; Kiatpongsan \& Norton, 2014). Taken together, this approach implies that lay people think of inequality in a comparative (rather than distributional) manner, and in terms of category exemplars. Nevertheless, as with the distributional measures discussed above, this comparative approach implies that lay perceptions of inequality are numeric.

A third approach to measuring perceptions of inequality involves people's nonnumerical visualizations. For instance, Kteily, Sheehy-Skeffington, and Ho (2017) examined the effect of social dominance orientation (SDO) on perceptions of inequality. Participants viewed a pictorial representation of the distribution of wealth in society (e.g., a vertical scale with increasing bags of money) before reporting their perception of the depicted inequality in each representation. Thus, rather than asking participants to generate their own perceived distribution of economic resources, the researchers provided them with a visual representation and asked them to report their interpretation of it. Participants' SDO was related to biased interpretation of the inequality, whereby those lower in SDO reported finding the same pictorial representation to be more unequal than did those higher in SDO.

Overall, this approach conceptualizes perceptions of inequality as an interpretation of often abstract, visual information rather than a numeric estimate. Again, variations have emerged. For instance, other work asked participants to assess the inequality between images of poor and rich individuals (Waldfogel et al., 2021) or between geotagged images of cities varying in wealth (Salesses, Schechtner, \& Hidalgo, 2013). By providing participants equivalent information regarding the actual amount of inequality as an input, researchers assessed perceptions above and beyond access to different information. However, this 
approach is highly dependent on specific stimuli and question stems (see also perceptions of inequality scales; e.g., García-Castro et al., 2019), which may influence interpretation.

\section{Outstanding Issues}

Together, the implied conceptualizations that stem from various approaches to measuring perceptions of inequality reveal some limitations. First, while diverse methods for assessing a construct are to be applauded, making sense of the varied results across these methods is difficult without clarity regarding the construct itself. Without such clarity, researchers may (and often do) draw conflicting conclusions. For instance, given the lack of clarity on how to measure lay perceptions of national inequality, it is not surprising that the literature suggests strikingly conflicting results, concluding that people both overestimate and underestimate the scope of inequality in society.

Second, a large body of research treats perceptions of inequality as numeric - that is, assuming that people walk around with numerical estimates of the inequality around them and attempting to "extract these numbers from people's heads" (e.g., Chambers et al., 2014; Hoy \& Mager, 2018; Kiatpongsan \& Norton, 2014; Norton \& Ariely, 2011). This highlights a common emphasis across the most popular measures in use today: researchers' ability to assess the accuracy of lay perceptions of inequality by comparing people's numeric estimates to actual indices of economic inequality. From this view, individuals are seen as calculating Homo economicus, assessing inequality (in)accurately and numerically, and then ostensibly acting on these assessments. ${ }^{2}$

Researchers' emphasis on accuracy forces their elicited perceptions to be comparable to popular economic indicators of inequality - that is, the kinds of measures that statisticians

\footnotetext{
${ }^{2}$ Indeed, ample debate exists in economics research regarding the "rational actor model," or so-called Homo economicus, as compared to models that incorporate sociologically and psychologically bounded rationality (Henrich et al., 2001; Ng \& Tseng, 2008; Persky, 1995; Simon, 1997; Thaler, 2000). Here, we suggest that the fundamentals of perceptual processing might also be included in this emerging model of human actors; thus, we might offer the term Homo percipiens.
} 
and economists might devise to assess the distribution of resources in society (e.g., the Gini coefficient, among other indicators). Unfortunately, such indicators are numeric, statistical, and complex, thus requiring measurements of "perceptions" to likewise take a numeric, statistical, and complex form. In the meantime, alternate goals to accuracy — such as reliability (are lay perceptions of inequality stable over time?), confidence (are people certain in their perceptions of inequality?), and robustness (are perceptions of inequality affected by superficial artifacts of the measurement or the environment?) - are given less consideration, to the detriment of research on the topic.

Third, many measures of perceptions of inequality implicitly define people's perceptions as "numeric representations of the distribution." But, while statistically savvy people may walk around the world thinking in terms of distributions, it is less clear whether lay people think about inequality in this way. Moreover, many people struggle to answer even simple distributional questions (e.g., Eriksson \& Simpson, 2012). Rather than focusing on distributions, human thinking is often categorical (e.g., is this a friend or foe; Fisher \& Keil, 2018), social comparative (e.g., myself versus others; Festinger, 1954; Gerber, Wheeler, \& Suls, 2018), and egocentric (e.g., myself now, in the past, or in the future; Albert, 1977; Markus \& Nurius, 1986; Markus \& Wurf; 1987; Wilson \& Ross, 2000). Consequently, measures of perceptions of inequality that focus on numerical distributions tend to conceptualize people's perceptions in a manner that does not necessarily reflect the way they think about the world.

To begin addressing these and other limitations, we build a theoretical framework that clarifies and conceptualizes the construct "perceptions" and thereby offers a path forward for future research on perceptions of inequality. 


\section{A Homo Percipiens Framework for Unpacking Perceptions of Inequality}

Human perception involves the identification and interpretation of cues in the environment, spanning from the building blocks of sensory and informational inputs to the psychological and behavioral outcomes of such inputs. As such, "perception" covers a lot of ground. Therefore, solely focusing on the accuracy of people's perceptions of inequality is unlikely to fully capture the processing involved in forming these perceptions (i.e., viewing participants as Homo percipiens). Such perceptual processing - mapped by research in perception, cognition, developmental, and social psychology — traces the origins of perception from initial stimulus identification through sensation, representation, judgment, and onto action. While the nuanced details of the vast process of human perception are beyond this paper's scope, one important conclusion is the need to treat perceptions of inequality as a process rather than a single outcome. We ground ourselves in this perspective, which we will use as scaffolding for our framework.

We propose a five-component process framework driving lay perceptions of inequality: access to, attention to, comprehension of, motivated processing of, and meaningful summarization of cues of inequality (see Figure 1). Based on this framework, we argue that people's perceptions of inequality depend on each component of the perceptual process. That is, people do not have static numbers in their minds representing inequality, but rather access, attend to, comprehend, motivatedly process, and meaningfully summarize different cues of inequality, each shaped by additional factors (e.g., cognitive biases). As a result, unlike objective indicators of inequality in the world, perceptions of inequality are fundamentally subjective. 


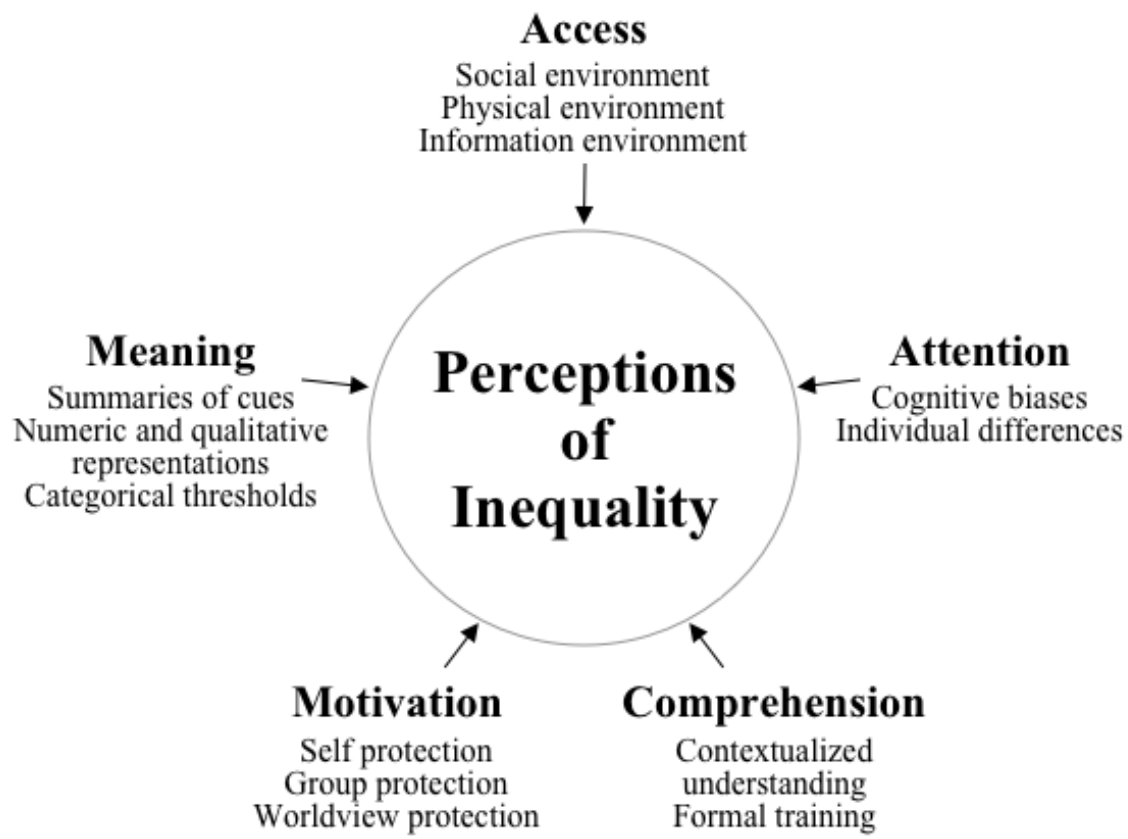

Figure 1. Unpacking Perceptions of Inequality from a Process Perspective. Perceptions of inequality do not represent a single, static construct, but rather are formed by a process of accessing, attending to, comprehending, motivatedly processing, and meaningfully summarizing cues of inequality.

We offer two important notes for this proposed framework. First, although we describe this framework in sequential steps loosely following the stages of visual perception, in reality these components do not necessarily follow a perfectly linear course. Just as visual perception emerges from interactive top-down (e.g., pre-existing knowledge) and bottom-up (e.g., contrast cues) processes, the components that form people's perceptions of inequality build on and influence one another over time, representing a dynamic relationship. As such, after describing each component, we consider how they may influence one another and unfold in a nonlinear fashion (e.g., concurrently, in different orders, and repeatedly over time).

Second, although we rely on models of visual perception as theoretical grounding for our framework, this analogy by no means implies that every component of visual perception applies to the perception of inequality, nor does it imply that inequality perception processes 
can be fully mapped onto the exact processes involved in visual perception. Rather, we suggest that grounding research on perceived inequality in the insights of visual perception can help unpack the process by which inequality is observed and perceived in everyday life. As such, we also incorporate insights from social, cognitive, and developmental perspectives into our framework.

\section{Access to Cues of Inequality}

The first component of inequality perception is to access available cues in the environment that provide information related to the existence and scope of inequality in society. Simply put, in order to develop a perception of inequality, people must first have information about it. Although such cues can be accessed from many different sources, they typically arise from people's immediate environments. Specifically, we focus on three major sources of such cues of inequality: who is around (social environment), what is around (physical environment), and what is in the media (informational environment). With these cues readily available, people are able to form perceptions of inequality even in the absence of objective or statistical information (e.g., reports of Gini coefficients, statistics about the "top $1 \%, "$ etc.).

First, people readily access cues in their social environment - or the economic composition of the people around them - to form perceptions about the scope of inequality in society (Iacono \& Ranaldi, 2020; Johnston \& Newman, 2016; Minkoff \& Lyons, 2019; Newman, Shah, \& Lauterbach, 2018; Nishi et al., 2015; Sands, 2017). For example, researchers analyzing open-ended responses about perceptions of inequality in Colombia found that people referenced socio-demographic groups, intergroup relations, and individuals they encountered in public spaces (García-Sánchez et al., 2018a; see also García-Castro et al., 2020). In turn, the diversity of people's social networks and the extent to which their local environments are segregated by income or wealth can readily influence their access to cues 
about inequality (e.g., Dawtry, Sutton, \& Sibley, 2015, 2019; Feiler \& Kleinbaum, 2015; Wang et al., 2018). As a consequence, two people living in the same city or state may nonetheless form very different perceptions of inequality in their environment based on the heterogeneity of socioeconomic backgrounds in their immediate personal and work relations. Indeed, given the intersection of racial and economic inequalities in the U.S., people whose networks or contact patterns are more racially diverse tend to be more accurate in their perceptions of racial wealth inequality than those with less diverse networks (Kraus, Rucker, et al., 2017; see also Brown \& Enos, 2021; Hamel \& Wilcox-Archuleta, 2020; Kraus, Onyeador, et al., 2019).

A second source of cues about inequality comes from people's physical environment, such as the houses in which their neighbors live, the cars they drive around, and the schools to which they send their children. Since social objects can serve as signals of the degree of variability in economic resources in one's environment (Sheehy-Skeffington, 2016), people may infer global trends of inequality from local physical cues. And, since many social institutions are often funded (at least partially) by local taxpayers, people may also use cues about local institutions (e.g., differences in the availability of well-funded schools, libraries, or museums) and public spaces (e.g., the prevalence of safe parks and playgrounds) as relevant information for the level of inequality in society. Indeed, people may be even more prone to access cues about physical spaces (e.g., associating a neighborhood's racial makeup with its level of perceived affluence) than about people (Bonam, Yantis, \& Taylor, 2020). More generally, the prevalence of status signals in the environment (e.g., designer brands, luxury cars) can serve as an important building block to perceptions of inequality, given the presumed presence of wealthy people (Sands \& de Kadt, 2020; Walasek \& Brown, 2015).

Finally, the media, or a person's informational environment, serves as a third source of cues about the scope of inequality. Specifically, media exposure can give people access to 
the economic resources of individuals across the distribution (e.g., salaries of CEOs, rates of homelessness, size of the middle class) as well as direct information about the distribution itself (e.g., comparing CEO salaries to worker salaries, discussing Gini coefficients). Importantly, while cues in people's social and physical environments are often observed locally, the media expands one's access to include less-localized cues about inequality. Given that the media portrays engaging and accessible information about wealth, poverty, and economic inequality, one may expect media consumption to influence perceptions (Kim, 2019). Preliminary evidence even suggests that when the media compellingly publicizes data about economic distributions, perceptions of inequality can become more accurate (PerezTruglia, 2020). At the same time, the fact that different groups can be over- or underrepresented in the media may also distort perceptions of inequality.

In sum, a combination of cues about inequality—accessed in people's social, physical, and informational environments - plays a substantial role in shaping perceptions.

\section{Attention}

Although access to inequality cues is necessary for forming perceptions, it is not sufficient. When forming perceptions of inequality, people must pay attention to relevant and accessible cues. In other words, just because a stimulus is available does not mean that people will notice or attend to it. Furthermore, when trying to estimate inequality, perceivers attend to and retrieve relevant past cues from memory. In this section, we outline how people attend to cues of inequality in their environments and how both cognitive biases and individual differences influence attention to shape perceptions.

First, people's attention to salient cues of social class influences their perceptions of inequality, even if they are not consciously aware of these cues entering their scope of attention. For example, people can rapidly and accurately assess status hierarchies and form impressions about social class (Kraus \& Keltner, 2009; Kraus, Park, \& Tan, 2017; Kraus, 
Torrez, et al., 2019; Phillips, Slepian, \& Hughes, 2018; see also Yamanashi Leib et al., 2020), suggesting an automatic mechanism for encoding information relevant to inequality. Similarly, people implicitly process both dominance cues (including vocal tone, body language, and facial expression; Dietze \& Knowles, 2016; Hall, Coats, \& LeBeau, 2005; Tiedens \& Fragale, 2003; Zitek \& Phillips, 2020) and more diffuse status cues (including clothing and facial attractiveness; Belmi \& Neale, 2014; Bjornsdottir \& Rule, 2017; Connor et al., 2021; Mahadevan, Gregg, \& Sedikides, 2019; Oh, Shafir, \& Todorov, 2020; Swencionis \& Fiske, 2018) which can later inform their perceptions of inequality (see also Yu \& Kilduff, 2019). Thus, attention to cues of social class- even when processed implicitly—may ultimately shape perceptions of inequality.

Second, the cues to which people attend when forming perceptions of inequality are substantially influenced by individual differences, including their demographics, ideology, and personal experiences. For example, a person's socioeconomic status not only shapes which cues are accessible for informing their views of inequality (e.g., local neighborhoods, social networks, etc.), but also affects whether and how they attend to those cues. Even when social cues are available, people of higher socioeconomic status tend to look less frequently at others compared to people of lower socioeconomic status (Dietze \& Knowles, 2016, 2020), and show less attunement to the needs of others (Stephens, Markus, \& Phillips, 2014; Stephens, Fryberg, \& Markus, 2011; see also Magee \& Smith, 2013). In contrast, frequent status changes across one's daily interactions (e.g., at work vs. at home) increase people's attention to status cues (Fernandes et al., 2021; see also Brown-Iannuzzi et al., 2015). Thus, by shaping attention to cues about one's relative place in the broader economic distribution, status itself may shape what people attend to and, consequently, their perceptions of inequality. Other individual and situational differences, such as fundamental motives, salient emotions, or political orientation, also influence attention (e.g., Kteily et al., 2017; see also 
Dunning \& Balcetis, 2013; Jost \& Amodio, 2012). For instance, social egalitarians attend to cues of inequality more readily in their physical and social environments (Waldfogel et al. 2021).

Attention matters not only for how people encode cues of inequality, but also for how they retrieve these cues when prompted to report their perceptions of inequality. Decades of research on judgment and decision-making offer insight into the heuristics people may use when retrieving cues about inequality (e.g., Kahneman, Slovic, Slovic, \& Tversky, 1982). When estimating inequality, people may rely on the availability heuristic, wherein information that is easier to recall has an outsized influence on decisions (Tversky \& Kahneman, 1973). For example, people may bring to mind salient exemplars of extremely wealthy or impoverished others (which are more mentally available than the median earner; Davidai \& Deri, 2019; Putnam-Farr \& Morewedge, 2020) which, in turn, may affect their broader perceptions of inequality (Evans, Kelley, \& Kolosi, 1992). Similarly, people may rely on salient, local information when forming perceptions of inequality, leading them to overly extrapolate from their own experience when estimating national inequality (Cruces, Perez-Truglia, \& Tetaz, 2013; Xu \& Garand, 2010). These biases may be further intensified by the media, which facilitates the recall of specific statistics (e.g., "CEO pay is 300 times that of worker pay," "Black Americans are five times more likely to be incarcerated than White Americans") and the lifestyles of those deemed noteworthy (e.g., celebrities), and which can subsequently create "availability cascades" (Kuran \& Sunstein, 1999).

Attention to and retrieval of cues may be further influenced by anchoring and adjustment, wherein estimates of inequality are biased by the numerical "anchors" that come to mind (Epley \& Gilovich, 2006; Tversky \& Kahneman, 1974). For instance, because different questions bring to mind different anchors and cues to consider, people's perceptions of inequality depend on whether they are asked about the portion of wealth owned by each 
quintile in society (e.g., Norton \& Ariely, 2011) or the absolute levels of income or wealth owned by the median member of each quintile (e.g., Eriksson \& Simpson, 2012). Likewise, people's tendency to impose categorical anchors on continuous data may influence how much attention they devote to different segments of the distribution (Fisher \& Keil, 2018).

Similarly, when thinking about the general level of income inequality in society, people may attend to and retrieve cues that are specific to racial or gender inequality, which may anchor their perceptions (Kim et al., 2016).

In sum, people selectively attend to cues about inequality in their environments, and both cognitive biases and individual differences influence the cues people attend to and retrieve when forming perceptions, both within and outside of conscious awareness.

\section{Comprehension}

In addition to accessing and attending to cues of inequality, people comprehend cues in ways that shape their overall perceptions. Just as attending to a collection of equidistant sticks organized in parallel to each other does not guarantee that people would comprehend the object as a ladder (e.g., Rosch, 1978; Rosch et al., 1976; see also Grill-Spector \& Kanwisher, 2005), seeing cues of status, wealth, and poverty does not guarantee that people would comprehend them, nor understand their relevance to inequality. Thus, although forming "perceptions of inequality" requires people to comprehend the cues to which they attend, understanding the abstract notion of "inequality" likely involves complex reasoning skills. We discuss comprehension in both natural settings (e.g., neighborhoods, work environments, etc.) and direct information settings (e.g., news, media reports, etc.).

First, when attending to physical and social cues in natural settings—-such as the presence of yachts in an area-people need to comprehend these cues vis-à-vis inequality. For instance, if people do not recognize an expensive status good as such — e.g., only one member of our research team could recognize a Christian Louboutin shoe as anything but a 
shoe, and even then only because she paid close attention to Lizzo lyrics — then accessing and attending to such cues will not lead them to develop perceptions of inequality (Berger \& Ward, 2010; Bellezza \& Berger, 2020). Indeed, to the extent that wealthy individuals often hide the true cost of their conspicuous consumption (Sherman, 2017), understanding cues of inequality may be even more difficult. As such, wealth can be especially difficult to observe: income may be more intuitive than wealth, stocks, or art (of which the vast majority of people have none).

Second, when attending to informational cues — such as media reports of Gini coefficients or decile comparisons of wealth - people must have a certain level of numeracy and statistical and financial proficiency to comprehend what this information conveys about inequality overall. For example, the fact that people provide lower estimates of inequality when considering the percentage of total wealth held by each quintile of the population than when considering the average wealth for each quintile (Norton \& Ariely, 2011; Eriksson \& Simpson, 2012) may not only reflect issues in attention (as described above), but also difficulties in comprehending the attended cues. Many people lack the numeracy and statistical training that may otherwise help them recognize cues of inequality—perhaps a chart of income distributions - for what they are (Eriksson \& Simpson, 2012; García-Castro et al., 2019; Hauser et al. 2019; Norton \& Ariely, 2011). This is not merely an issue for lay perception, given that even experts fall prey to various cognitive biases and statistical errors (e.g., Kahan et al., 2017; see also Koehler, Brenner, \& Griffin, 2002; Soyer \& Hogarth, 2012; Tversky \& Kahneman, 1971).

Moreover, ample work on mathematical learning suggests that people are more likely to represent numerical concepts contextually, rather than rely on more formal mathematical representations (Carraher, Carraher, \& Schliemann, 1985; Leahy, 1983). For instance, people living in poverty are more accurate than the wealthy when calculating grocery store spending, 
but not when solving other arithmetic problems, suggesting that accuracy partly depends on contextual relevance (Shah et al., 2018). Thus, expecting people to perform sophisticated calculations and comprehend cues regarding dispersion parameters (e.g., a Gini coefficient) that are unfamiliar and/or irrelevant to their contexts may be unrealistic. Consequently, when people are given statistical information regarding inequality and prompted to report their perceptions, they may not always comprehend this information, unless they have the requisite training and experience to do so (Nisbett et al., 1983).

In sum, differences in comprehension — or the extent to which people make a connection between cues and the overall concept — will influence perceptions of inequality.

\section{Motivated Processing}

Even when people have identical access to informational cues, pay the same attention to these cues, and have similar comprehension abilities, motivated processing may still lead them to differing representations of inequality. Indeed, perceptual processing is prone to motivational influences that lead people to perceive the world in ways that fit, protect, or verify their existing experiences and needs (Hennes et al., 2012; Kunda, 1990; Lerner, 1977; Van den Bos, 2009; Jost \& Hunyady, 2003, 2005; Kay \& Eibach, 2012; Sidanius \& Pratto, 1999). Here, we focus on motives to protect the self, the group, and worldviews as they pertain to perceptions of inequality.

First, people are motivated to preserve their material and psychological resources, including feelings of self-regard and moral worth (Cohen \& Sherman, 2014; Deci \& Ryan, 2000; see also Anderson et al., 2015). In the case of inequality, people with higher subjective status are more likely to believe that the status quo is fair and just and, as a result, less likely to support changes to the economic system (Brown-Iannuzzi et al., 2015; Karadja et al., 2017; McCoy \& Major, 2007). Similarly, because benefiting from an unequal system can be morally uncomfortable, people who actively gain from inequality (e.g., class privileged; 
Phillips \& Lowery, 2020; see also Newman, Shah, \& Lauterbach, 2018; Swencionis \& Fiske, 2018) or who believe that they would be able to do so in the future (e.g., mobility beliefs; Day \& Fiske, 2019; see also Davidai \& Gilovich, 2015; Kim, 2019; Shariff, Wiwad, \& Aknin, 2016) are often motivated to perceive less inequality than exists. Consequently, the motivation to protect the self can minimize how much inequality people see in society.

Second, the motivation to preserve the material and psychological resources of one's group can similarly affect how people process cues about inequality (Sidanius \& Pratto, 1999; Tajfel \& Turner, 1979). Because people like to see the groups to which they belong as positive, they often underplay the scope of inequalities that benefit their group by downplaying the disadvantages faced by other groups in society, exaggerating the difficulties faced by their own group, or both (Phillips \& Lowery, 2015, 2018; Vollhardt, 2020; Wilkins et al., 2015; Young \& Sullivan, 2016; see also Davidai \& Gilovich, 2016). Further, concerns about intergroup competition can motivate perceptions. For instance, zero-sum beliefs about race can lead White Americans to perceive less bias against Black Americans than against Whites (Norton \& Sommers, 2011). Likewise, group-protective beliefs about the nature of racism (e.g., whether racism is a structural problem) can motivate White Americans to disregard or even distort cues about inequality (Rucker, Duker, \& Richeson, 2019; Onyeador et al., 2020; Unzueta \& Lowery, 2008).

Finally, people are motivated to protect their worldviews-beliefs, values, and associated ideologies about how the world works. Such worldviews include preferences for hierarchy (Sidanius \& Pratto, 1999), maintaining the status quo (Kay et al., 2009), and belief in a just world (Lerner, 1980). In turn, such worldviews can influence the processing of inequality cues. For example, to justify their preferences for a more hierarchical society, people higher or lower in SDO tend to underestimate or overestimate (respectively) the level of inequality in society, even when faced with direct and relevant cues about inequality 
(Kteily et al., 2017; Lucas \& Kteily, 2018). Similarly, belief in a just world and the motivation to see the status quo as legitimate (i.e., system justification) are associated with the denial of racial and gender inequalities (Davidai \& Ongis, 2019; García-Sánchez et al., 2019; Goudarzi et al., 2020; Jefferson, Neuner, \& Pasek, 2020; Kay \& Jost 2003; Kraus, Rucker, et al., 2017; Kraus, Onyeador et al., 2019; Townsend et al., 2010). Thus, to the extent that people believe the world is just and that inequality is fair, their motivation to maintain their worldviews can shape their perceptions of inequality.

In sum, although accessing, attending to, and comprehending cues about inequality are necessary for forming accurate perceptions, motivations may nevertheless cloud these perceptions by affecting how people process these cues.

\section{Meaningful Summary Representation}

Our remaining component of the perceptual process involves turning each of the preceding inputs into a meaningful summary representation of "inequality." That is, beyond numeric estimates, perception entails the process of imbuing inputs with meaning. ${ }^{3}$

First, when summarizing cues into a meaningful representation, they must be judged as relevant to inequality, weighted appropriately, and combined accordingly. As a result, two individuals may equally access, attend to, comprehend, and even motivatedly process cues to inequality and yet ultimately combine them differently, resulting in differing perceptions of inequality. For example, whereas wealthy individuals may minimize local cues of poverty as nondiagnostic of the general level of inequality in society, a personal experience with poverty may lead people to assign more weight to such cues and, consequently, to perceive greater inequality (Irwin, 2018). Likewise, individual differences in moral preferences, such as

\footnotetext{
${ }^{3}$ We do not mean to imply that the meaning component is a "final perception." Indeed, summary representations of inequality ought to be far from final, constantly updating in the face of new situations, motivations, information, and experiences (Hohwy, 2013, 2017).
} 
equity sensitivity (Huseman, Hatfield, \& Miles, 1987; see also Day et al., 2014), may affect how people weigh cues of inequality when creating a summary representation.

Second, when imbuing their summary representation with meaning, people are unlikely to separate quantitative cues from their qualitative interpretations of them. In particular, people likely reference why they believe that the observed inequality exists in the first place, and what they believe are its consequences. For instance, because people are more sensitive to inequity than inequality (Frank et al., 2015; Li, Spitzer, \& Olson, 2014; LoBue et al., 2011; Tyler, 2011), they are much less averse to inequality caused by a meritocratic process rather than a non-meritocratic process (Bjørnskov et al., 2013; see also Connor et al., 2020; Chow \& Galak, 2012; McCoy \& Major, 2007; Savani \& Rattan, 2012; Shaw, 2014; Trevor et al., 2012). Relatedly, people may perceive the same objective level of inequality differently based on their beliefs regarding its potential personal, interpersonal, and societal consequences (e.g., Campbell \& Kay, 2014; Mitchell \& Tetlock, 2009). Indeed, concepts such as "excessive," "ideal," or "insufficient" inequality all reflect a judgment of how the perceived quantitative level compares to some subjective (and often implicit) threshold for the "right" amount of inequality.

Third, because conceptual reasoning is often categorical rather than numeric and consists of "fuzzy" representations of core concepts (Reyna, 2012), people likely conceptualize "inequality" categorically rather than via numeric summarization (see also Fisher \& Keil, 2018). Interestingly, while researchers have been focusing on accurate numerical estimates of inequality, public opinion polls often rely on measures that more closely resemble this intuitive manner in which people may characterize inequality in their heads - not in numbers, but in categories (e.g., Horowitz, Igielnik, \& Kochnar, 2020). As such, people's tolerance of rising inequality may be better predicted by their perception that circumstances fail to meet their conceptual threshold for what constitutes "inequality," as 
compared to their (mis)perceptions of numeric indicators. Once people's generalized representations of inequality cross this conceptual threshold, they may act.

In turn, this likely makes lay definitions of inequality particularly important in shaping perceptions (see also García-Castro et al., 2019; García-Sánchez et al., 2018b; McCall, 2013; Irwin, 2018; Schmalor \& Heine, 2021). Specifically, people may conceptualize "inequality" as "a problematic allocation of resources" rather than "an unequal allocation of resources" (as researchers often do). In turn, such individual conceptualizations may shape the cues that are activated when people think about inequality, leading to the emergence of their perceptions. For instance, when evaluating whether inequality is "problematic," people may rely on morally salient signals, including its underlying causes (i.e., how the inequality was brought about). People may also rely on thresholds, such as their perceptions of whether basic needs are met (García-Sánchez et al., 2018b; Hagerty \& Barasz, 2020), or whether some have limitless ease and luxury (e.g., Bapuji, Ertug, \& Shaw, 2020; Cohen et al., 2017; Kim et al., 2016; Phillips \& Lowery, 2020). In addition, people likely rely on their own subjective experience, such as their sense of financial insecurity (Martin \& Côté, 2019; Meuris \& Leana, 2018), and other local, personalized, and self-relevant cues (e.g., social comparisons with The Joneses; humanized narratives of hardship; László, 2008; Phillips, Martin, \& Belmi, 2020; Weick, 1995), rather than global, decontextualized, economic indicators (e.g., percentile cues).

In sum, when creating a summary representation of inequality, people aggregate multiple cues, including their qualitative beliefs about the distribution of resources in society. Ultimately, the ascription of meaning to create a "perception of inequality" ought to shape affective, cognitive, and behavioral responses. Thus, to fully understand how people perceive inequality, it is important to attend to how people interpret and make sense of it. Next, we discuss how the five components of the perception process (access, attention, comprehension, 
motivated processing, and meaning) interact in nonlinear, iterative, and dynamic ways to shape perceptions of inequality.

\section{The Nonlinear, Iterative, Dynamic Nature of Perceptions of Inequality}

Our theoretical framework suggests that lay perceptions of inequality are better understood not as static, numeric estimates, but as the result of dynamic psychological processes that we have organized into five key components. Each component can be used to better understand the complex phenomenon of perceptions of inequality. For ease of elucidation and reading, we have presented these components sequentially, as an analogy to the stages of visual perception. However, our framework is not composed of stages of perceptions of inequality, but rather of components of such perceptions, and as such do not necessarily follow a perfectly linear sequence. Just as visual perception is impacted by topdown and bottom-up processes, the components that form perceptions of inequality build on and influence one another, representing a nonlinear, iterative, and dynamic process (see Figure 2). 

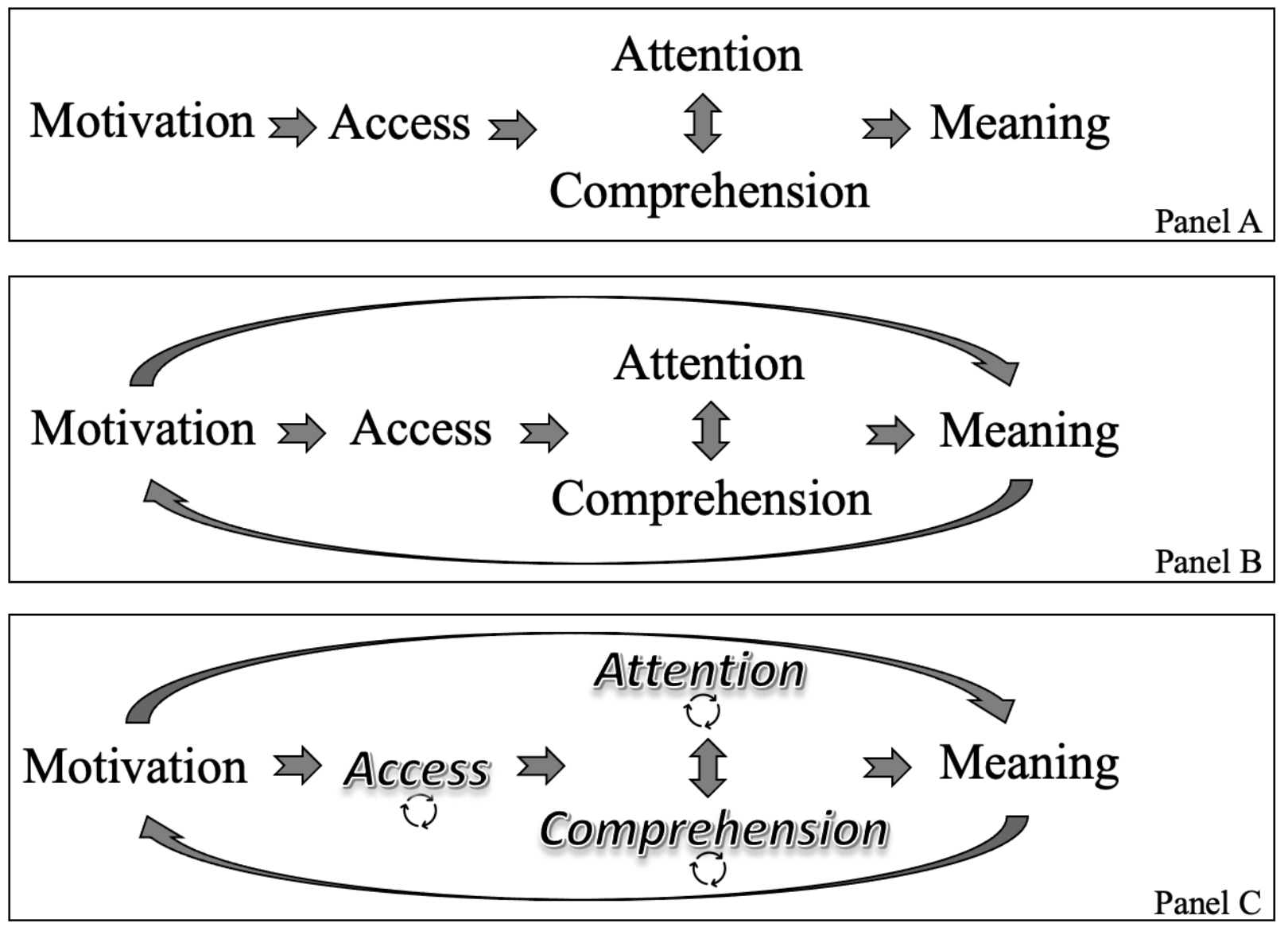

Figure 2. Panel A (nonlinear), Panel B (nonlinear + iterative), Panel C (nonlinear + iterative + dynamic).

First, consider the nonlinearity of perceptions of inequality, that is, that the components of perception might unfold in many different orders. For instance, people who comprehend a pair of Louboutin shoes as expensive might notice and attend them as a signal of inequality, but those who are oblivious to these shoes' sticker price might first need to understand their significance in order to attend to them. As such, attention to and comprehension of cues of inequality may unfold in either order or may even occur simultaneously. Second, consider the potential iterative nature of the components of our framework. Rather than forming perceptions of inequality once, people are likely to continuously revise their perceptions through access to new cues, attention to these cues, improved comprehension, and so on. In other words, perceptions of inequality are likely formed through a feedback loop, updating each of the components of this process repeatedly 
over time. Finally, since people and their environments are in constant flux, perceptions of inequality should similarly be construed dynamically. Motivations change, comprehension evolves, and attentional processes develop over time. As such, lay perceptions of inequality similarly change, evolve, and develop over time.

To illustrate, consider a wealthy individual whose everyday access to cues of inequality can be explored through their daily commute. On their way to work, this person might listen to the news, learn about politics and economic trends, and hear stories about different people's experiences (cues in their social and informational environments). This person might also drive through neighborhoods of varying income levels, observing homes, schools, and public parks (cues in their physical environment). In addition to having access to such cues of inequality (e.g., passing through low-income neighborhoods or listening to the radio discuss wealth concentration in America), this individual must attend to these cues (e.g., by paying close attention to the world outside their car or to news content), comprehend these cues as relevant to inequality (e.g., by attributing the state of run-down buildings to disparate resources), be motivated to perceive them as equitable or inequitable (e.g., by judging differences in income as due to situational vs. dispositional forces), and create a meaningful summary representation of the amount of inequality in their city (e.g., by comparing their perceptions with their internal threshold for what counts as a "problematic" level of inequality).

Critically, these five components of perception are unlikely to unfold neatly and sequentially. For instance, the individual's motivation and ideological worldviews may affect their access to cues of inequality (e.g., by leading them to move to more economically homogenous areas and to change their commute to bypass low-income neighborhoods; for an 
example in the context of racial segregation, see Anicich et al., 2021) or the attention they devote to such cues (e.g., by turning on their radio and intentionally averting their gaze when faced with cues of poverty). Thus, rather than following access and attention, the motivation to maintain social hierarchies can instead direct these components of inequality perception.

Similarly, given that the individual experiences their commute daily, the process of forming their perceptions of inequality is likely to be iterative. Forming a summary representation of inequality in one's city at the end of the daily commute represents just a single point in this person's cyclical process, likely affecting the attention they will pay to cues on subsequent days (e.g., overlooking cues of inequality if they already believe inequality is low) and their comprehension of the cues to which they attend (e.g., interpreting cues as irrelevant if they had previously concluded that inequality is low). Thus, just as thresholds for judgment change following repeated exposure (Levari et al., 2019), perceptions of inequality might change as people continually encounter different cues over time.

Lastly, given the dynamic nature of this process, substantial changes in each of the components may affect this individual's perceptions of inequality. For instance, changes in their access to cues (e.g., high-income individuals that spend time in low-income areas inevitably gentrify such areas, thus reducing their access to cues of inequality) may lead the individual to a different perception. Likewise, major external shocks may also shift perceptions: emerging evidence suggests that the COVID-19 pandemic has not only increased attention to inequality, but also increased people's systemic explanations for it (versus dispositional explanations; Wiwad et al., 2021).

In this way, our framework highlights how perceptions of inequality are generated by nonlinear, iterative, and dynamic interactions among components. Indeed, the components we 
outline above may materialize concurrently, in different orders, and repeatedly over shorter and longer time frames. As such, we suggest that perceptions of inequality are best understood as a process. This understanding provides a novel conceptual window for researchers to examine the complex ways that the components of perception can interact with each other to form (and update) perceptions of inequality.

\section{Implications of the Proposed Framework for Future Research}

We suggest that future research should consider perceptions of economic inequality as a multi-component process. To encourage inequality researchers to adopt this approach to perceptions, we demonstrate how the framework above can be used to better specify research questions, methods, and interpretations of findings.

\section{Asking More Precise Research Questions}

Research on perceptions of inequality has predominantly focused on the outputs of inequality perceptions, seeking to understand their consequences for well-being, redistributive preferences, and other outcomes (e.g., Hauser \& Norton, 2017; Niehues 2014). Our framework suggests that it is also critical to study the inputs of such perceptions, as these may play a unique and dynamic role in predicting different outcomes. Researchers might use our framework to examine the role played by each component in predicting outcomes of interest, how these components change over time and across contexts, or how they work together to produce lay representations of "inequality" as a whole.

When developing research questions and hypotheses, researchers may benefit from focusing on specific components of perception, given that "perceptions" as a whole represent a number of constructs and processes. This could include, for example, delineating which cues people have access to, which cues attract their attention, how individuals assign different weights to different cues in order to recognize inequality, or even how different inequality cues get translated into numerical estimates. Researchers may also choose to specify a single 
component of the perceptual process that they would like to study instead of looking at perceptions of inequality more broadly. Rather than asking questions like "How do perceptions of inequality influence redistributive preferences?," researchers might, for example, specifically study the effects of access to cues or particular motivations on these same outcomes. By asking questions that are more precisely specified, researchers may be able to generate better theoretical models that allow for more apt empirical predictions.

\section{Developing More Precise Methods to Understand Perceptions of Inequality}

A significant portion of the literature has focused on extracting numerical estimates of inequality to represent perceptions as a whole. However, such elicitations of the "numbers in people's heads" may bias perceptions of inequality by shaping respondents' attention and affecting their comprehension of inequality cues. Thus, the methods researchers use to assess perceptions of inequality can potentially inflate or deflate the extent to which people perceive society as unequal (e.g., Eriksson \& Simpson, 2012; Schwarz \& Oyserman, 2001).

We argue that researchers should move beyond this operationalization of perceptions and instead opt for more precise measures. By creating and adopting measures of specific components of perception, researchers can better represent the lived experience of inequality, rather than primarily focusing on flawed cognitive representations. Consider the following sets of methods, compiled in Table 1, that might apply to each component of our framework. 


\begin{tabular}{|c|c|c|c|c|}
\hline Access & Attention & Comprehension & Motivation & Meaning \\
\hline $\begin{array}{l}\text { Bonam et al., } 2020 \\
\text { Brown \& Enos, } 2021 \\
\text { Dawtry et al., 2015 } \\
\text { Dawtry et al., 2019 } \\
\text { Feiler \& Kleinbaum, } 2015 \\
\text { García-Sánchez et al., 2018a } \\
\text { García-Castro et al., 2020 } \\
\text { Hamel \& Wilcox-Archuleta, } \\
2020 \\
\text { Iacono \& Ranaldi, } 2020 \\
\text { Johnston \& Newman, } 2016 \\
\text { Kim, 2019 } \\
\text { Kraus, Park, et al., } 2017 \\
\text { Minkoff \& Lyons, } 2019 \\
\text { Newman et al., 2018 } \\
\text { Nishi et al., 2015 } \\
\text { Perez-Truglia, } 2020 \\
\text { Sands, 2017 } \\
\text { Sands \& de Kadt, } 2020 \\
\text { Wang et al., 2018 }\end{array}$ & $\begin{array}{l}\text { Belmi \& Neale, } 2014 \\
\text { Bjornsdottir \& Rule, } 2017 \\
\text { Brown-Iannuzzi et al., } 2015 \\
\text { Connor et al., 2021 } \\
\text { Cruces et al., 2013 } \\
\text { Davidai \& Deri, } 2019 \\
\text { Dietze \& Knowles, } 2016 \\
\text { Dietze \& Knowles, 2020 } \\
\text { Epley \& Gilovich, 2006 } \\
\text { Evans et al., 1992 } \\
\text { Fernandes et al., } 2021 \\
\text { Hall et al., 2005 } \\
\text { Kim et al., 2016 } \\
\text { Kraus et al., 2009 } \\
\text { Kraus, Park, et al., } 2017 \\
\text { Kraus, Torrez, et al., } 2019 \\
\text { Kteily et al., 2017 } \\
\text { Magee \& Smith, 2013 } \\
\text { Mahadevan et al., 2019 } \\
\text { Oh et al., 2020 } \\
\text { Phillips, Slepian, et al., } 2018 \\
\text { Putnam-Farr \& Morewedge, } 2020 \\
\text { Stephens et al., 2011 } \\
\text { Swencionis \& Fiske, } 2018 \\
\text { Tiedens \& Fragale, 2003 } \\
\text { Waldfogel et al., 2021 } \\
\text { Xu \& Garand, 2010 } \\
\text { Yamanashi Leib et al., } 2020 \\
\text { Zitek \& Phillips, 2020 }\end{array}$ & $\begin{array}{l}\text { Bellezza \& Berger, } 2020 \\
\text { Berger \& Ward, } 2010 \\
\text { Carraher et al., } 1985 \\
\text { Eriksson \& Simpson, } 2012 \\
\text { García-Castro et al., } 2019 \\
\text { Hauser et al., } 2017 \\
\text { Leahy, 1983 } \\
\text { Nisbett et al., } 1983 \\
\text { Norton \& Ariely, } 2011 \\
\text { Page \& Goldstein, } 2016 \\
\text { Shah et al., 2018 } \\
\text { Soyer \& Hogarth, } 2012\end{array}$ & 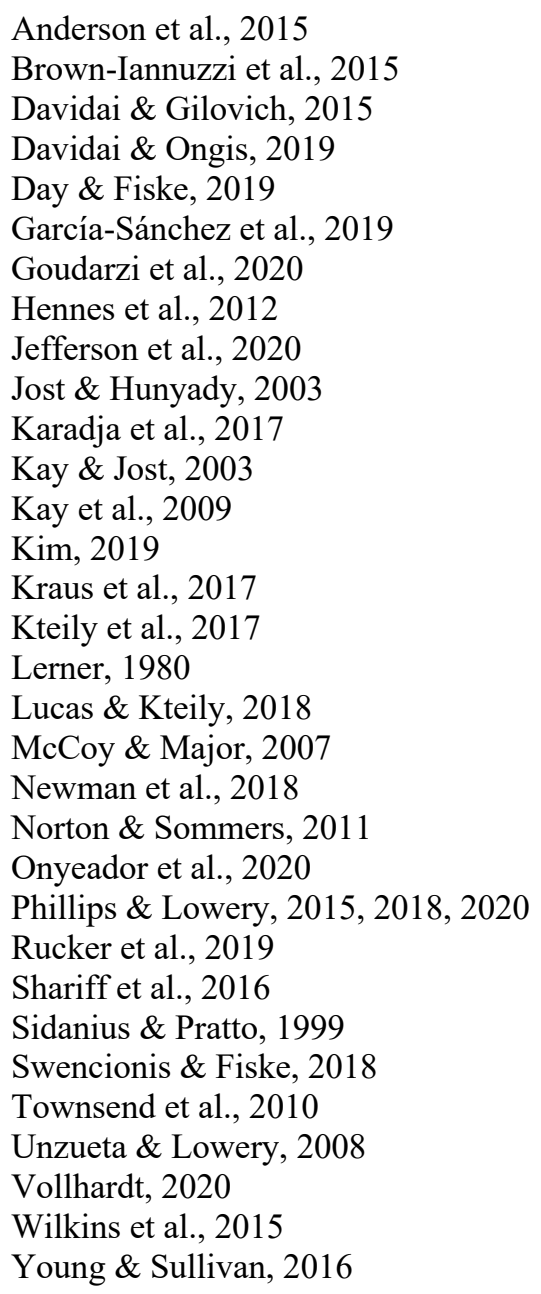 & $\begin{array}{l}\text { Bjørnskov et al., } 2013 \\
\text { Chow \& Galak, } 2012 \\
\text { Cohen et al., 2017 } \\
\text { Day et al., 2014 } \\
\text { Frank et al., } 2015 \\
\text { García-Castro et al., } 2019 \\
\text { García-Sánchez et al., 2018b } \\
\text { Hagerty \& Barasz, } 2020 \\
\text { Horowitz et al., 2020 } \\
\text { Huseman et al., 1987 } \\
\text { Irwin, 2018 } \\
\text { Li et al., 2014 } \\
\text { LoBue et al., 2011 } \\
\text { Martin \& Côté, } 2019 \\
\text { McCall, 2013 } \\
\text { Meuris \& Leana, 2018 } \\
\text { Mitchell \& Tetlock, } 2009 \\
\text { Phillips, Martin, et al., } 2020 \\
\text { Savani \& Rattan, } 2012 \\
\text { Schmalor \& Heine, } 2021 \\
\text { Shaw, 2014 } \\
\text { Trevor et al., 2012 } \\
\text { Tyler, 2011 }\end{array}$ \\
\hline
\end{tabular}

Table 1. Perceptions of Economic Inequality by Component Emphasized. To aid researchers in identifying the literature most relevant to each facet of perception, we organize emerging work relevant to perceptions of inequality by which component it targets in the perceptual process framework. 
To measure access, researchers might employ spatial analyses (see Brown \& Enos, 2021; Wang et al., 2018) or computational methods (see Guest \& Martin, 2021) to study participants' physical and social environments in more granular ways. Researchers can also use more objective indicators of inequality cues, such as salary data within a given locale or organization (see Perez-Truglia, 2020; Card et al., 2012), to understand how access to particular cues shapes perceptions. Researchers interested in understanding the role of attention to inequality cues might use measurement tools like eye-tracking (see Dietze \& Knowles, 2016) to capture people's awareness of and attention to the social status of others. To study comprehension, researchers might rely on survey measures that probe participants' understanding and application of information about inequality, such as from popular media (see Kuziemko et al., 2015). Researchers seeking to understand motivation might use manipulations of subjective status (see Brown-Iannuzzi et al., 2015) to examine its effects on the outcome of interest. Lastly, researchers interested in meaning might employ methods from the broader social sciences, such as qualitative and interview approaches (Irwin, 2018), to probe participants' abstract representations of high-level inequality.

In measuring specific components of perception, researchers ought to consider how other components of the perception process affect or interfere with their measures of interest. As noted, we believe that the components delineated in our framework may often unfold in a non-sequential fashion. For instance, motivation shapes both access and attention (Dietze \& Knowles, 2016; Kteily et al., 2017), and cognitive biases related to attention (e.g., anchoring) can also activate motivated processing (e.g., "last place aversion"; Kuziemko et al., 2014). Researchers should outline which components of perception are of interest given the question at hand and consider how these components might influence each other (or be influenced by other, non-focal components) as they develop their hypotheses and measures. 


\section{Interpreting Findings More Meaningfully}

Perceptions of inequality have demonstrated predictive power for meaningful outcomes, but research focused only on accuracy sheds little insight into why these perceptions matter. In other words, asking participants to generate quantifiable estimates of inequality cannot tell us how they understand or feel about the inequality they see in the world. As such, these findings alone cannot explain why perceptions matter. By looking instead at specific components of perception, we may be able to make more informed inferences about how and why perceptions influence people's attitudes and behavior.

More specifically, understanding people's current perceptions and the way they interpret them is the first step in unpacking downstream consequences. For example, while informational interventions about the state of inequality have been largely ineffective in changing people's redistributive preferences (Kuziemko et al., 2015), this may not come as a surprise when viewed through the lens cast by our proposed framework. Specifically, any or all of the perceptual components above may contribute to people holding on to their existing perceptions about inequality even when confronted with accurate information about it. Consequently, our framework suggests that effective interventions may need to target multiple components of the perceptual process in order to change people's beliefs and, in turn, their behaviors.

\section{Is Accuracy the Only Goal?}

Unpacking the multi-component process behind perceptions of inequality also calls into question whether achieving perceptual accuracy should always be researchers' goal. Given the myriad perceptual processing components involved, achieving accuracy is likely to be very challenging. First, treating perception as a process makes it clear that individuals likely do not represent inequality numerically_people are unlikely to walk around tracking 
Gini coefficients in their minds. ${ }^{4}$ Furthermore, we do not know whether people's emergent perceptions of inequality need to first be activated in some way and, if so, what tends to activate them. For instance, it is possible that numeric estimates of inequality only arise as a response to researchers' measurements (e.g., once activated) rather than reflect a true spontaneous perception. Once prompted by researchers to think about inequality, people may initiate a process of searching for and attending to relevant cues in the environment, which they then aggregate into a representation to which they ultimately ascribe meaning. Perhaps as a result of this mismatch between lay perceptions of inequality and researchers' conceptualization of these perceptions, people may give very different numeric estimates of inequality when asked about it in different ways.

Second, even when offered veridical numeric information to inform their inequality perceptions, this numeric cue is not separable from participants' own interpretation and injection of meaning. For some questions (e.g., what is an individual's current estimate of the Gini coefficient in their country?), advanced training may be required to achieve "accurate" perceptions. Even then, it is unlikely that individuals will be able to perfectly access, attend, and comprehend inequality cues, or possess the objectivity to process and summarize these without other motivations (e.g., see Kteily et al., 2017; Norton \& Sommers, 2011). In fact, when aiming to answer such numeric questions about perceptions of inequality, people may begin with a rationale for why they want to reach a certain judgment in the first place (e.g., to fit their ideology) and form their perceptions accordingly. To the extent that researchers are interested in accuracy and inaccuracy vis-à-vis some economic indicator, we encourage future work to specify during which perceptual components they expect accuracy to be

\footnotetext{
${ }^{4}$ We concede that there may be some exceptions to this. Perhaps Christine Lagarde, current President of the European Central Bank, and some of her colleagues, who we presume access such information from statistical models that provide the numbers directly and have the requisite training to interpret them, may do so at times.
} 
affected, and how individual differences, contextual cues, motivational processes, and temporal dynamics may influence the degree of (in)accuracy of such estimates.

Third, the accuracy of the reported "numbers in people's heads" may matter less than prior research presumes because it is unlikely to drive important outcomes. When scholars investigate individuals' perceptions of numeric indicators, such as the distribution of wealth across percentiles, we do so because we hope to use these perceptions to access individuals' gestalt representations of "inequality." But our research needs to be embedded in the broader question of what people think this inequality means, including how they think the inequality came to be, how they think it will impact them, whether they see it as a problem, and how they feel about those attributes (i.e., meta-perceptions). By clarifying the process of perception, and perhaps moving away from questions of accuracy, we might be better positioned to understand which specific aspects of perception drive outcomes. In particular, future research is needed to understand how people represent and define inequality concepts in their everyday contexts.

Finally, to the extent that studying the accuracy of numeric perceptions is likely to be the goal at least sometimes (even if not all the time), additional empirical specificity is still warranted. In light of our earlier discussion of the wide variety of cues pertaining to inequality, and the processing and weighting of said cues, we highlight the importance of understanding exactly what exactly people are reporting their perceptions of (and how this compares to researchers' own definitions of inequality; Jachimowicz, Davidai et al., 2020).

In sum, we hope that the proposed conceptualization of perceptions of inequality as a multi-component, nonlinear, iterative, and dynamic process can offer inequality researchers a framework for asking more precise questions, adopting more precise methods, drawing more meaningful interpretations, and defining more comprehensive goals for their future investigations. 


\section{Moving Toward a Process Conceptualization of Perceptions of Inequality}

We argue that inequality researchers will benefit from a more conceptually precise specification of "perception," treating perception as an ongoing process including five key components: access to, attention to, comprehension of, motivated processing of, and meaningful summary representation of cues. Treating the perception of inequality as a process, rather than as a veridical snapshot recorded by Homo economicus, requires an apt consideration of the psychological processes and mental representations involved in forming perceptions. Ultimately, perception requires access to information (stimuli, attention) as well as higher-order processing of that information (comprehension, motivation) to result in an ever-shifting summary representation (meaning).

We do not intend for the proposed framework to be exhaustive of every factor that may affect perceptual processing, and additional components or sub-components may also play a role. More research is needed to elucidate these processes. Perceptions of inequality are studied in an impressive variety of fields, from economics and political science to psychology and sociology. We highlight that there is room to become even more inclusive, and to clarify the construct of perceptions across all of these fields as a result.

In particular, we encourage scholars of inequality to engage more fully with existing work done by scholars of perceptual and conceptualization processes. This includes, but is not limited to, work on semantic, mathematical, and moral reasoning, including developmental perspectives (e.g., Anderson, Pyke, \& Finchman, 2016; Kroll \& Potter, 1984; McLoyd, 2019); work on perceptual processing, including social vision (e.g., Adams et al., 2011; Collins \& Olson, 2014; Funder, 1995); work on cognitive development, memory, and knowledge formation (e.g., Boyce-Jacino \& DeDeo, 2020; Katz, Wright, \& Bodily, 2007; Reyna, 2012); and work on information processing, including cognitive and motivational biases in judgment and decision-making (e.g., Anderson, 2014; Kahneman et al., 1982; 
Kunda, 1990). We argue that this should include collaborations between researchers studying perceptions of inequality and those in fields previously viewed as unrelated, in order to arrive at work that more aptly treats such perceptions as a process.

Research on inequality has burgeoned across the social sciences, as inequality itself has grown across many societies. While ample theorizing suggests that inequality ought to predict a host of important psychosocial outcomes, the evidence suggests that perceptions of it may be more important predictors. Nevertheless, mixed findings persist. Here, we suggest that this stems in part from a lack of specificity regarding the process of how inequality is perceived. Our framework offers a guide for future work, which we hope provides better insights into how people form perceptions of inequality, and thus predict their behavior. 


\section{References}

Acemoglu, D., \& Robinson, J. A. (2006). De facto political power and institutional persistence. American Economic Review, 96(2), 325-330.

Adams, R. B., Albohn, D. N., \& Kveraga, K. (2017). Social vision: Applying a socialfunctional approach to face and expression perception. Current Directions in Psychological Science, 26(3), 243-248. https://doi.org/10.1177/0963721417706392

Albert, S. (1977). Temporal comparison theory. Psychological Review, 84(6), 485.

Anderson, N. H. (2014). Contributions to information integration theory: Volume 1: Cognition. Psychology Press.

Anderson, C., Hildreth, J. A. D., \& Howland, L. (2015). Is the desire for status a fundamental human motive? A review of the empirical literature. Psychological Bulletin, 141(3), 574.

Anderson, J. R., Pyke, A. A., \& Fincham, J. M. (2016). Hidden stages of cognition revealed in patterns of brain activation. Psychological Science, 27(9), 1215-1226. https://doi.org/10.1177/0956797616654912

Anicich, E., Jachimowicz, J., Osborne, M., \& Phillips, L. T. (2021, February 16). Structuring local environments to avoid diversity: Anxiety drives Whites' geographical and institutional self-segregation preferences. https://doi.org/10.31234/osf.io/yzpr2

Ashok, V., Kuziemko, I., \& Washington, E. (2015). Support for redistribution in an age of rising inequality: New stylized facts and some tentative explanations (No. w21529). National Bureau of Economic Research.

Bapuji, H., Ertug, G., \& Shaw, J. D. (2020). Organizations and societal economic inequality: A review and way forward. Academy of Management Annals, 14(1), 60-91. https://doi.org/10.5465/annals.2018.0029

Bartels, L. M. (2005). Homer gets a tax cut: Inequality and public policy in the American mind. Perspectives on Politics, 3(01). https://doi.org/10.1017/S1537592705050036

Bechtel, M. M., Liesch, R., \& Scheve, K. F. (2018). Inequality and redistribution behavior in a give-or-take game. Proceedings of the National Academy of Sciences, 115(14), 3611-3616. https://doi.org/10.1073/pnas.1720457115

Bellezza, S., \& Berger, J. (2020). Trickle-round signals: When low status is mixed with high. Journal of Consumer Research, 47(1), 100-127.

Belmi, P., \& Neale, M. (2014). Mirror, mirror on the wall, who's the fairest of them all? Thinking that one is attractive increases the tendency to support inequality.

Organizational Behavior and Human Decision Processes, 124(2), 133-149. https://doi.org/10.1016/j.obhdp.2014.03.002

Berger, J., \& Ward, M. (2010). Subtle signals of inconspicuous consumption. Journal of Consumer Research, 37(4), 555-569. https://doi.org/10.1086/655445

Bjornsdottir, R. T., \& Rule, N. O. (2017). The visibility of social class from facial cues. Journal of Personality and Social Psychology, 113(4), 530-546. https://doi.org/10.1037/pspa0000091

Bjørnskov, C., Dreher, A., Fischer, J. A. V., Schnellenbach, J., \& Gehring, K. (2013). Inequality and happiness: When perceived social mobility and economic reality do not match. Journal of Economic Behavior \& Organization, 91, 75-92. https://doi.org/10.1016/j.jebo.2013.03.017

Black, J. F., \& Davidai, S. (2020). Do rich people "deserve" to be rich? Charitable giving, internal attributions of wealth, and judgments of economic deservingness. Journal of Experimental Social Psychology, 90, 104011. https://doi.org/10.1016/j.jesp.2020.104011 
Bonam, C., Yantis, C., \& Taylor, V. J. (2020). Invisible middle-class Black space: Asymmetrical person and space stereotyping at the race-class nexus. Group Processes \& Intergroup Relations, 23(1), 24-47.

Boyce-Jacino, C., \& DeDeo, S. (2020). Opacity, obscurity, and the geometry of questionasking. Cognition, 196, 104071. https://doi.org/10.1016/j.cognition.2019.104071

Brown, J. R., \& Enos, R. D. (2021). The measurement of partisan sorting for 180 million voters. Nature Human Behaviour, 1-11. https://doi.org/10.1038/s41562-021-01066-z

Brown-Iannuzzi, J. L., Lundberg, K. B., Kay, A. C., \& Payne, B. K. (2015). Subjective status shapes political preferences. Psychological Science, 26(1), 15-26. https://doi.org/10.1177/0956797614553947

Buttrick, N. R., \& Oishi, S. (2017). The psychological consequences of income inequality. Social and Personality Psychology Compass, 11(3), e12304. https://doi.org/10.1111/spc3.12304

Campbell, T. H., \& Kay, A. C. (2014). Solution aversion: On the relation between ideology and motivated disbelief. Journal of Personality and Social Psychology, 107(5), 809.

Card, D., Mas, A., Moretti, E., \& Saez, E. (2012). Inequality at work: The effect of peer salaries on job satisfaction. American Economic Review, 102(6), 2981-3003. https://doi.org/10.1257/aer.102.6.2981

Carraher, T. N., Carraher, D. W., \& Schliemann, A. D. (1985). Mathematics in the streets and in schools. British Journal of Developmental Psychology, 3(1), 21-29.

Chambers, J. R., Swan, L. K., \& Heesacker, M. (2014). Better off than we know: Distorted perceptions of incomes and income inequality in America. Psychological Science, 25(2), 613-618. https://doi.org/10.1177/0956797613504965

Chow, R. M., \& Galak, J. (2012). The effect of inequality frames on support for redistributive tax policies. Psychological Science, 23(12), 1467-1469. https://doi.org/10.1177/0956797612450035

Cohen, G. L., \& Sherman, D. K. (2014). The psychology of change: Self-affirmation and social psychological intervention. Annual Review of Psychology, 65, 333-371.

Cohen, D., Shin, F., Liu, X., Ondish, P., \& Kraus, M. W. (2017). Defining social class across time and between groups. Personality and Social Psychology Bulletin, 43(11), 15301545.

Collins, J. A., \& Olson, I. R. (2014). Knowledge is power: How conceptual knowledge transforms visual cognition. Psychonomic Bulletin \& Review, 21(4), 843-860. https://doi.org/10.3758/s13423-013-0564-3

Connor, P., Varney, J., Keltner, D., \& Chen, S. (2021). Social class competence stereotypes are amplified by socially signaled economic inequality. Personality and Social Psychology Bulletin, 47(1), 89-105.

Connor, P., Stancato, D., Yildirim, U., Lee, S., \& Chen, S. (2020). Inequality in the minimal group paradigm: How relative wealth and its justification influence ingroup bias. Journal of Experimental Social Psychology, 88, 103967.

Cruces, G., Perez-Truglia, R., \& Tetaz, M. (2013). Biased perceptions of income distribution and preferences for redistribution: Evidence from a survey experiment. Journal of Public Economics, 98, 100-112. https://doi.org/10.1016/j.jpubeco.2012.10.009

Davidai, S., \& Deri, S. (2019). The second pugilist's plight: Why people believe they are above average but are not especially happy about it. Journal of Experimental Psychology: General, 148(3), 570.

Davidai, S., \& Gilovich, T. (2015). Building a more mobile America-One income quintile at a time. Perspectives on Psychological Science, 10(1), 60-71. 
Davidai, S., \& Gilovich, T. (2016). The headwinds/tailwinds asymmetry: An availability bias in assessments of barriers and blessings. Journal of Personality and Social Psychology, 111(6), 835.

Davidai, S., \& Ongis, M. (2019). The politics of zero-sum thinking: The relationship between political ideology and the belief that life is a zero-sum game. Science Advances, 5(12), eaay3761.

Dawtry, R. J., Sutton, R. M., \& Sibley, C. G. (2015). Why wealthier people think people are wealthier, and why it matters: From social sampling to attitudes to redistribution. Psychological Science, 26(9), 1389-1400. https://doi.org/10.1177/0956797615586560

Dawtry, R. J., Sutton, R. M., \& Sibley, C. G. (2019). Social sampling, perceptions of wealth distribution, and support for redistribution. In J. Jetten \& K. Peters (Eds.), The social psychology of inequality (pp. 432). Springer.

Day, M. V., \& Fiske, S. T. (2019). Understanding the nature and consequences of social mobility beliefs. In J. Jetten \& K. Peters (Eds.), The social psychology of inequality (pp. 365-380). Springer.

Day, M. V., Fiske, S. T., Downing, E. L., \& Trail, T. E. (2014). Shifting liberal and conservative attitudes using moral foundations theory. Personality and Social Psychology Bulletin, 40(12), 1559-1573.

Deci, E. L., \& Ryan, R. M. (2000). The" what" and" why" of goal pursuits: Human needs and the self-determination of behavior. Psychological Inquiry, 11(4), 227-268.

Dietze, P., \& Knowles, E. D. (2016). Social class and the motivational relevance of other human beings: Evidence from visual attention. Psychological Science, 27(11), 15171527. https://doi.org/10.1177/0956797616667721

Dietze, P., \& Knowles, E. D. (2020). Social class predicts emotion perception and perspective-taking performance in adults. Personality and Social Psychology Bulletin, 47(1), 42-56. https://doi.org/10.1177/0146167220914116

Dunning, D., \& Balcetis, E. (2013). Wishful seeing: How preferences shape visual perception. Current Directions in Psychological Science, 22(1), 33-37. https://doi.org/10.1177/0963721412463693

Elenbaas, L. (2019). Perceptions of economic inequality are related to children's judgments about access to opportunities. Developmental Psychology, 55(3), 471-481. https://doi.org/10.1037/dev0000550

Elgar, F. J., Gariepy, G., Dirks, M., Walsh, S. D., Molcho, M., Cosma, A., MalinowskaCieslik, M., Donnelly, P. D., \& Craig, W. (2019). Association of early-life exposure to income inequality with bullying in adolescence in 40 countries. JAMA Pediatrics, 173(7), e191181. https://doi.org/10.1001/jamapediatrics.2019.1181

Engelhardt, C., \& Wagener, A. (2014). Biased perceptions of income inequality and redistribution. Beiträge zur Jahrestagung des Vereins für Socialpolitik 2014: Evidenzbasierte Wirtschaftspolitik - Session: Redistribution and Subjective Wellbeing, No. A20-V3.

Epley, N., \& Gilovich, T. (2006). The anchoring-and-adjustment heuristic: Why the adjustments are insufficient. Psychological Science, 17(4), 311-318.

Eriksson, K., \& Simpson, B. (2012). What do Americans know about inequality? It depends on how you ask them. Judgment and Decision Making, 7(6), 6.

Evans, M. D. R., Kelley, J., \& Kolosi, T. (1992). Images of class: Public perceptions in Hungary and Australia. American Sociological Review, 57(4), 461. https://doi.org/10.2307/2096095

Feiler, D. C., \& Kleinbaum, A. M. (2015). Popularity, similarity, and the network extraversion bias. Psychological Science, 26(5), 593-603. https://doi.org/10.1177/0956797615569580 
Fernandes, C., Yu, S., Howell, T., Kilduff, G., Pettit, N., \& Brooks, A. W. (2021). Status variance: Higher variance in one's status across groups improves interpersonal outcomes but harms subjective well-being. Organizational Behavior and Human Decision Processes.

Festinger, L. (1954). A theory of social comparison processes. Human Relations, 7(2), 117140.

Fisher, M., \& Keil, F. C. (2018). The binary bias: A systematic distortion in the integration of information. Psychological Science, 29(11), 1846-1858. https://doi.org/10.1177/0956797618792256

Frank, D. H., Wertenbroch, K., \& Maddux, W. W. (2015). Performance pay or redistribution? Cultural differences in just-world beliefs and preferences for wage inequality. Organizational Behavior and Human Decision Processes, 130, 160-170.

Franko, W. W. (2017). Understanding public perceptions of growing economic inequality. State Politics \& Policy Quarterly, 17(3), 319-348. https://doi.org/10.1177/1532440017707799

Funder, D. C. (1995). On the accuracy of personality judgment: A realistic approach. Psychological Review, 102(4), 652-670.

García-Castro, J. D., Rodríguez-Bailón, R., \& Willis, G. B. (2020). Perceiving economic inequality in everyday life decreases tolerance to inequality. Journal of Experimental Social Psychology, 90, 104019. https://doi.org/10.1016/j.jesp.2020.104019

García-Castro, J. D., Willis, G. B., \& Rodríguez-Bailón, R. (2019). I know people who can and who cannot: A measure of the perception of economic inequality in everyday life. The Social Science Journal, 56(4), 599-608.

García-Sánchez, E., Van der Toorn, J., Rodríguez-Bailón, R., \& Willis, G. B. (2019). The vicious cycle of economic inequality: The role of ideology in shaping the relationship between "what is" and "what ought to be" in 41 countries. Social Psychological and Personality Science, 10(8), 991-1001. https://doi.org/10.1177/1948550618811500

García-Sánchez, E., Willis, G. B., Rodríguez-Bailón, R., García-Castro, J. D., PalacioSañudo, J., Polo, J., \& Rentería-Pérez, E. (2018a). Perceptions of economic inequality in Colombian daily life: More than unequal distribution of economic resources. Frontiers in Psychology, 9. https://doi.org/10.3389/fpsyg.2018.01660

García-Sánchez, E., Willis, G. B., Rodríguez-Bailón, R., Palacio Sañudo, J., David Polo, J., \& Rentería Pérez, E. (2018b). Perceptions of economic inequality and support for redistribution: The role of existential and utopian standards. Social Justice Research, 31(4), 335-354. https://doi.org/10.1007/s11211-018-0317-6

Gerber, J. P., Wheeler, L., \& Suls, J. (2018). A social comparison theory meta-analysis 60+ years on. Psychological Bulletin, 144(2), 177.

Gimpelson, V., \& Treisman, D. (2018). Misperceiving inequality. Economics \& Politics, 30(1), 27-54. https://doi.org/10.1111/ecpo.12103

Goffman, E. (1974). Frame analysis: An essay on the organization of experience. Harvard University Press.

Goudarzi, S., Pliskin, R., Jost, J. T., \& Knowles, E. D. (2020). Economic system justification predicts muted emotional responses to inequality. Nature Communications, 11(1), 19.

Gramsci, A. (1971). Selections from the prison notebooks of Antonio Gramsci. New York: International Publishers.

Grill-Spector, K., \& Kanwisher, N. (2005). Visual recognition: As soon as you know it is there, you know what it is. Psychological Science, 16(2), 152-160. 
Guest, O., \& Martin, A. E. (2021). How computational modeling can force theory building in psychological science. Perspectives on Psychological Science. https://doi.org/10.1177/1745691620970585

Guinjoan, M., \& Rico, G. (2018). How perceptions of inequality between countries diminish trust in the European Union: Experimental and observational evidence. Political Psychology, 39(6), 1289-1303.

Hagerty, S. F., \& Barasz, K. (2020). Inequality in socially permissible consumption. Proceedings of the National Academy of Sciences, 117(25), 1408414093.

Hall, J. A., Coats, E. J., \& LeBeau, L. S. (2005). Nonverbal behavior and the vertical dimension of social relations: A meta-analysis. Psychological Bulletin, 131(6), 898924.

Hamel, B. T., \& Wilcox-Archuleta, B. (2020). Black Workers in White Places: Daytime Racial Diversity and White Public Opinion.

Hauser, O. P., Kraft-Todd, G. T., Rand, D. G., Nowak, M. A., \& Norton, M. I. (2019). Invisible inequality leads to punishing the poor and rewarding the rich. Behavioural Public Policy, 1-21.

Hauser, O. P., \& Norton, M. I. (2017). (Mis)perceptions of inequality. Current Opinion in Psychology, 18, 21-25. https://doi.org/10.1016/j.copsyc.2017.07.024

Hennes, E. P., Nam, H. H., Stern, C., \& Jost, J. T. (2012). Not all ideologies are created equal: Epistemic, existential, and relational needs predict system-justifying attitudes. Social Cognition, 30(6), 669-688.

Henrich, J., Boyd, R., Bowles, S., Camerer, C., Fehr, E., Gintis, H., \& McElreath, R. (2001). In search of homo economicus: Behavioral experiments in 15 small-scale societies. American Economic Review, 91(2), 73-78. https://doi.org/10.1257/aer.91.2.73

Hohwy, J. (2013). The predictive mind. Oxford University Press.

Hohwy, J. (2017). Priors in perception: Top-down modulation, Bayesian perceptual learning rate, and prediction error minimization. Consciousness and Cognition, 47, 75-85. https://doi.org/10.1016/j.concog.2016.09.004

Horowitz, J. M., Igielnik, R., \& Kochhar, R. (2020). Most Americans say there is too much economic inequality in the US, but fewer than half call it a top priority. https://pewrsr.ch/32hTbQo

Hoy, C., \& Mager, F. (2018). Can information about inequality and social mobility change preferences for redistribution? Evidence from randomized controlled trials in 11 high and middle-income countries. Tax and Transfer Policy Institute Working Paper.

Hoy, C., Cognome, N., \& Merdikawati, N. (2020). How does information about inequality shape voting intentions and preferences for redistribution? Evidence from a randomized survey experiment in Indonesia (No. 500). ECINEQ Society for the Study of Economic Inequality Working Paper Series.

Huseman, R. C., Hatfield, J. D., \& Miles, E. W. (1987). A New Perspective on Equity Theory: The Equity Sensitivity Construct. Academy of Management Review, 12(2), 232-234.

Iacono, R., \& Ranaldi, M. (2020). The nexus between perceptions of inequality and preferences for redistribution. The Journal of Economic Inequality, 1-18.

Irwin, S. (2018). Lay perceptions of inequality and social structure. Sociology, 52(2), 211227. https://doi.org/10.1177/0038038516661264

Jachimowicz, J. M., Davidai, S., Goya-Tocchetto, D., Szaszi, B., Day, M. V., Tepper, S. J., Phillips, L. T., Mirza, M. U., Ordabayeva, N., \& Hauser, O. P. (2020). Inequality in Researcher's Minds. Available online at: https://psyarxiv.com/gn2z5. 
Jefferson, H., Neuner, F. G., \& Pasek, J. (2020). Seeing blue in black and white: Race and perceptions of officer-involved shootings. Perspectives on Politics, 1-19.

Johnston, C. D., \& Newman, B. J. (2016). Economic inequality and US public policy mood across space and time. American Politics Research, 44(1), 164-191.

Jost, J. T., \& Amodio, D. M. (2012). Political ideology as motivated social cognition: Behavioral and neuroscientific evidence. Motivation and Emotion, 36(1), 55-64. https://doi.org/10.1007/s11031-011-9260-7

Jost, J., \& Hunyady, O. (2003). The psychology of system justification and the palliative function of ideology. European Review of Social Psychology, 13(1), 111-153.

Jost, J. T., \& Hunyady, O. (2005). Antecedents and consequences of system-justifying ideologies. Current Directions in Psychological Science, 14(5), 260-265.

Kahan, D. M., Peters, E., Dawson, E. C., \& Slovic, P. (2017). Motivated numeracy and enlightened self-government. Behavioural public policy, 1(1), 54-86.

Kahneman, D., Slovic, S. P., Slovic, P., \& Tversky, A. (1982). Judgment under uncertainty: Heuristics and biases. Cambridge University Press.

Karadja, M., Mollerstrom, J., \& Seim, D. (2017). Richer (and holier) than thou? The effect of relative income improvements on demand for redistribution. The Review of Economics and Statistics, 99(2), 201-212. https://doi.org/10.1162/REST_a_00623

Katz, J. (2006). Issues in the comparative cognition of abstract-concept learning. Comparative Cognition \& Behavior Reviews, 2. https://doi.org/10.3819/ccbr.2008.20005

Katz, J. S., Wright, A. A., \& Bodily, K. D. (2007). Issues in the comparative cognition of abstract-concept learning. Comparative Cognition \& Behavior Reviews, 2, 79.

Kay, A. C., Gaucher, D., Peach, J. M., Laurin, K., Friesen, J., Zanna, M. P., \& Spencer, S. J. (2009). Inequality, discrimination, and the power of the status quo: Direct evidence for a motivation to see the way things are as the way they should be. Journal of personality and social psychology, 97(3), 421.

Kay, A. C., \& Eibach, R. P. (2012). The ideological toolbox: Ideologies as tools of motivated social cognition. The SAGE Handbook of Social Cognition, 495-515.

Kay, A. C., \& Jost, J. T. (2003). Complementary justice: effects of "poor but happy" and "poor but honest" stereotype exemplars on system justification and implicit activation of the justice motive. Journal of Personality and Social Psychology, 85(5), 823.

Kenworthy, L., \& McCall, L. (2008). Inequality, public opinion and redistribution. SocioEconomic Review, 6(1), 35-68.

Kiatpongsan, S., \& Norton, M. I. (2014). How much (more) should CEOs make? A universal desire for more equal pay. Perspectives on Psychological Science, 9(6), 587-593. https://doi.org/10.1177/1745691614549773

Kim, E., Pedersen, R. T., \& Mutz, D. C. (2016). Misunderstanding income inequality and its policy consequences. Midwest Political Science Association Conference.

Kim, E. (2019). Entertaining beliefs in economic mobility [Dissertation]. University of Pennsylvania.

Knell, M., \& Stix, H. (2020). Perceptions of inequality. European Journal of Political Economy, 65, 101927.

Koehler, D. J., Brenner, L., \& Griffin, D. (2002). The calibration of expert judgment: Heuristics and biases beyond the laboratory. In T. Gilovich, D. Griffin, \& D. Kahneman (Eds.), Heuristics and biases: The psychology of intuitive judgment (p. 686-715). Cambridge University Press.

Kraus, M. W., Onyeador, I. N., Daumeyer, N. M., Rucker, J. M., \& Richeson, J. A. (2019). The misperception of racial economic inequality. Perspectives on Psychological Science, 14(6), 899-921. 
Kraus, M. W., Park, J. W., \& Tan, J. J. X. (2017). Signs of social class: The experience of economic inequality in everyday life. Perspectives on Psychological Science, 12(3), 422-435.

Kraus, M. W., \& Keltner, D. (2009). Signs of socioeconomic status: A thin-slicing approach. Psychological science, 20(1), 99-106.

Kraus, M. W., Rucker, J. M., \& Richeson, J. A. (2017). Americans misperceive racial economic equality. Proceedings of the National Academy of Sciences, 114(39), 10324-10331.

Kraus, M. W., Torrez, B., Park, J. W., \& Ghayebi, F. (2019). Evidence for the reproduction of social class in brief speech. Proceedings of the National Academy of Sciences, 116(46), 22998-23003. https://doi.org/10.1073/pnas.1900500116

Kroll, J. F., \& Potter, M. C. (1984). Recognizing words, pictures, and concepts: A comparison of lexical, object, and reality decisions. Journal of Verbal Learning and Verbal Behavior, 23(1), 39-66. https://doi.org/10.1016/S0022-5371(84)90499-7

Kteily, N. S., Sheehy-Skeffington, J., \& Ho, A. K. (2017). Hierarchy in the eye of the beholder: (Anti-)egalitarianism shapes perceived levels of social inequality. Journal of Personality and Social Psychology, 112(1), 136-159. https://doi.org/10.1037/pspp0000097

Kuhn, A. (2019). The subversive nature of inequality: Subjective inequality perceptions and attitudes to social inequality. European Journal of Political Economy, 59, 331-344. https://doi.org/10.1016/j.ejpoleco.2019.04.004

Kunda, Z. (1990). The case for motivated reasoning. Psychological Bulletin, 108(3), 480498. https://doi.org/10.1037/0033-2909.108.3.480

Kuo, E. E., Kraus, M. W., \& Richeson, J. A. (2020). High-status exemplars and the misperception of the Asian-white wealth gap. Social Psychological and Personality Science, 11(3), 397-405.

Kuran, T., \& Sunstein, C. R. (1998). Availability cascades and risk regulation. Stanford Law Review, 51, 683.

Kuziemko, I., Buell, R. W., Reich, T., \& Norton, M. I. (2014). "Last-place aversion": Evidence and redistributive implications. The Quarterly Journal of Economics, 129(1), 105-149. https://doi.org/10.1093/qje/qit035

Kuziemko, I., Norton, M. I., Saez, E., \& Stantcheva, S. (2015). How elastic are preferences for redistribution? Evidence from randomized survey experiments. American Economic Review, 105(4), 1478-1508. https://doi.org/10.1257/aer.20130360

László, J. (2008). The science of stories: An introduction to narrative psychology. Routledge.

Leahy, R. L. (1983). Development of the conception of economic inequality: II. Explanations, justifications, and concepts of social mobility and change. Developmental Psychology, 19(1), 111.

Lerner, M. J. (1977). The justice motive: Some hypotheses as to its origins and forms 1. Journal of Personality, 45(1), 1-52.

Lerner, M. J. (1980). The belief in a just world. In The belief in a just world (pp. 9-30). Springer, Boston, MA.

Levari, D. E., Gilbert, D. T., Wilson, T. D., Sievers, B., Amodio, D. M., \& Wheatley, T. (2018). Prevalence-induced concept change in human judgment. Science, 360(6396), $1465-1467$.

Li, V., Spitzer, B., \& Olson, K. R. (2014). Preschoolers reduce inequality while favoring individuals with more. Child Development, 85(3), 1123-1133.

LoBue, V., Nishida, T., Chiong, C., DeLoache, J. S., \& Haidt, J. (2011). When getting something good is bad: Even three-year-olds react to inequality. Social Development, 20(1), 154-170. 
Lucas, B. J., \& Kteily, N. S. (2018). (Anti-)egalitarianism differentially predicts empathy for members of advantaged versus disadvantaged groups. Journal of Personality and Social Psychology, 114(5), 665-692. https://doi.org/10.1037/pspa0000112

Magee, J. C., \& Smith, P. K. (2013). The social distance theory of power. Personality and Social Psychology Review, 17(2), 158-186.

Mahadevan, N., Gregg, A. P., \& Sedikides, C. (2019). Is self-regard a sociometer or a hierometer? Self-esteem tracks status and inclusion, narcissism tracks status. Journal of Personality and Social Psychology, 116(3), 444-466. https://doi.org/10.1037/pspp0000189

Markus, H., \& Nurius, P. (1986). Possible selves. American Psychologist, 4 1(9), 954.

Markus, H., \& Wurf, E. (1987). The dynamic self-concept: A social psychological perspective. Annual Review of Psychology, 38(1), 299-337.

Martin, S. R., \& Côté, S. (2019). Social class transitioners: Their cultural abilities and organizational importance. Academy of Management Review, 44(3), 618-642.

McCall, L. (2013). The undeserving rich: American beliefs about inequality, opportunity, and redistribution. Cambridge University Press.

McCoy, S. K., \& Major, B. (2007). Priming meritocracy and the psychological justification of inequality. Journal of Experimental Social Psychology, 43(3), 341-351. https://doi.org/10.1016/j.jesp.2006.04.009

McLoyd, V. C. (2019). How children and adolescents think about, make sense of, and respond to economic inequality: Why does it matter? Developmental Psychology, 55(3), 592-600. https://doi.org/10.1037/dev0000691

Meltzer, A. H., \& Richard, S. F. (1981). A rational theory of the size of government. Journal of Political Economy, 89(5), 914-927. https://doi.org/10.1086/261013

Meuris, J., \& Leana, C. (2018). The price of financial precarity: Organizational costs of employees' financial concerns. Organization Science, 29(3), 398-417.

Minkoff, S. L., \& Lyons, J. (2019). Living with inequality: Neighborhood income diversity and perceptions of the income gap. American Politics Research, 47(2), 329-361. https://doi.org/10.1177/1532673X17733799

Mitchell, G., \& Tetlock, P. E. (2009). Disentangling reasons and rationalizations: Exploring perceived fairness in hypothetical societies. In J. T. Jost, A. C. Kay, \& H. Thorisdottir (Eds.), Social and Psychological Bases of Ideology and System Justification (pp. 126157). Oxford University Press. https://doi.org/10.1093/acprof:oso/9780195320916.003.006

Newman, B. J., Shah, S., \& Lauterbach, E. (2018). Who sees an hourglass? Assessing citizens' perception of local economic inequality. Research \& Politics, 5(3), 2053168018793974.

Ng, I. C., \& Tseng, L. M. (2008). Learning to be sociable: the evolution of homo economicus. American Journal of Economics and Sociology, 67(2), 265-286.

Niehues, J. (2014). Subjective perceptions of inequality and redistributive preferences: An international comparison (No. 2). Cologne Institute for Economic Research IWTRENDS Discussion Paper.

Nisbett, R. E., Krantz, D. H., Jepson, C., \& Kunda, Z. (1983). The use of statistical heuristics in everyday inductive reasoning. Psychological Review, 90(4), 339-363.

Nishi, A., Shirado, H., Rand, D. G., \& Christakis, N. A. (2015). Inequality and visibility of wealth in experimental social networks. Nature, 526(7573), 426-429. https://doi.org/10.1038/nature15392

Norton, M. I. (2014). Unequality: Who gets what and why it matters. Policy Insights from the Behavioral and Brain Sciences, 1(1), 151-155. https://doi.org/10.1177/2372732214550167 
Norton, M. I., \& Ariely, D. (2011). Building a better America-One wealth quintile at a time. Perspectives on psychological science, 6(1), 9-12.

Norton, M. I., \& Ariely, D. (2013). American's desire for less wealth inequality does not depend on how you ask them. Judgment and Decision Making, 8(3), 393-394.

Norton, M. I., \& Sommers, S. R. (2011). Whites see racism as a zero-sum game that they are now losing. Perspectives on Psychological Science, 6(3), 215-218. https://doi.org/10.1177/1745691611406922

Oh, D., Shafir, E., \& Todorov, A. (2020). Economic status cues from clothes affect perceived competence from faces. Nature Human Behaviour, 4(3), 287-293. https://doi.org/10.1038/s41562-019-0782-4

Onyeador, I. N., Daumeyer, N. M., Rucker, J. M., Duker, A., Kraus, M. W., \& Richeson, J. A. (2020). Disrupting beliefs in racial progress: Reminders of persistent racism alter perceptions of past, but not current, racial economic equality. Personality and Social Psychology Bulletin, 47(5), 753-765. https://doi.org/10.1177/0146167220942625

Osberg, L., \& Smeeding, T. (2006). "Fair" inequality? Attitudes toward pay differentials: The United States in comparative perspective. American Sociological Review, 71(3), 450473.

Page, L., \& Goldstein, D. G. (2016). Subjective beliefs about the income distribution and preferences for redistribution. Social Choice and Welfare, 47(1), 25-61. https://doi.org/10.1007/s00355-015-0945-9

Perez-Truglia, R. (2020). The effects of income transparency on well-being: Evidence from a natural experiment. American Economic Review, 110(4), 1019-1054. https://doi.org/10.1257/aer.20160256

Persky, J. (1995). Retrospectives: The Ethology of Homo Economicus. Journal of Economic Perspectives, 9(2), 221-231. https://doi.org/10.1257/jep.9.2.221

Petkanopoulou, K., Sánchez-Rodríguez, Á., Willis, G. B., Chryssochoou, X., \& RodríguezBailón, R. (2018). Two countries in crisis: Economic inequality in the EU and disidentification with Europe in Spain and Greece. Journal of Cross-Cultural Psychology, 49(6), 888-906. https://doi.org/10.1177/0022022117751201

Peyton, K. (2020). Does trust in government increase support for redistribution? Evidence from randomized survey experiments. American Political Science Review, 114(2), 596-602. https://doi.org/10.1017/S0003055420000076

Phillips, L. T., \& Lowery, B. S. (2015). The hard-knock life? Whites claim hardships in response to racial inequity. Journal of Experimental Social Psychology, 61, 12-18.

Phillips, L. T., \& Lowery, B. S. (2018). Herd invisibility: The psychology of racial privilege. Current Directions in Psychological Science, 27(3), 156-162.

Phillips, L. T., \& Lowery, B. S. (2020). I ain't no fortunate one: On the motivated denial of class privilege. Journal of Personality and Social Psychology, 119(6), 14031422. https://doi.org/10.1037/pspi0000240

Phillips, L. T., Martin, S. R., \& Belmi, P. (2020). Social class transitions: Three guiding questions for moving the study of class to a dynamic perspective. Social and Personality Psychology Compass, 14(9), e12560.

Phillips, L. T., Slepian, M. L., \& Hughes, B. L. (2018). Perceiving groups: The people perception of diversity and hierarchy. Journal of Personality and Social Psychology, 114(5), 766-785. https://doi.org/10.1037/pspi0000120

Pickett, K. E., \& Wilkinson, R. G. (2015). Income inequality and health: A causal review. Social Science \& Medicine, 128, 316-326. https://doi.org/10.1016/j.socscimed.2014.12.031 
Pratto, F., Sidanius, J., Stallworth, L. M., \& Malle, B. F. (1994). Social dominance orientation: A personality variable predicting social and political attitudes. Journal of Personality and Social Psychology, 67(4), 741.

Putnam-Farr, E., \& Morewedge, C. K. (2021). Which social comparisons influence happiness with unequal pay? Journal of Experimental Psychology: General, 150(3), 570582. https://doi.org/10.1037/xge0000965

Reyna, V. F. (2009). Fuzzy-trace theory. In M. Kattan, Encyclopedia of medical decision making. SAGE. https://doi.org/10.4135/9781412971980.n155

Reyna, V. F. (2012). A new intuitionism: Meaning, memory, and development in FuzzyTrace Theory. Judgment and Decision making.

Rosch, E., \& Lloyd, B. B. (Eds.). (1978). Cognition and categorization.

Rosch, E., Mervis, C. B., Gray, W. D., Johnson, D. M., \& Boyes-Braem, P. (1976). Basic objects in natural categories. Cognitive Psychology, 8(3), 382-439.

Rucker, J., Duker, A., \& Richeson, J. (2019). Structurally Unjust: How Lay Beliefs about Racism Relate to Perceptions of and Responses to Racial Inequality in Criminal Justice. Available online at: https://doi.org/10.31234/osf.io/sjkeq

Salesses, P., Schechtner, K., \& Hidalgo, C. A. (2013). The collaborative image of the city: Mapping the inequality of urban perception. PLOS ONE, 8(7), e68400.

Sánchez-Rodríguez, Á., Jetten, J., Willis, G., \& Rodríguez-Bailón, R. (2019). High economic inequality makes us feel less wealthy. International Review of Social Psychology, 32(1).

Sands, M. L. (2017). Exposure to inequality affects support for redistribution. Proceedings of the National Academy of Sciences, 114(4), 663-668. https://doi.org/10.1073/pnas.1615010113

Sands, M. L., \& de Kadt, D. (2020). Local exposure to inequality raises support of people of low wealth for taxing the wealthy. Nature, 586(7828), 257-261. https://doi.org/10.1038/s41586-020-2763-1

Savani, K., \& Rattan, A. (2012). A choice mind-set increases the acceptance and maintenance of wealth inequality. Psychological Science, 23(7), 796-804. https://doi.org/10.1177/0956797611434540

Schmalor, A., \& Heine, S. J. (2021). The construct of subjective economic inequality. Social Psychological and Personality Science. https://doi.org/10.1177/1948550621996867

Schwarz, N., \& Oyserman, D. (2001). Asking questions about behavior: Cognition, communication, and questionnaire construction. American Journal of Evaluation, 34.

Shah, A. K., Zhao, J., Mullainathan, S., \& Shafir, E. (2018). Money in the mental lives of the poor. Social Cognition, 36(1), 4-19. https://doi.org/10.1521/soco.2018.36.1.4

Shariff, A. F., Wiwad, D., \& Aknin, L. B. (2016). Income mobility breeds tolerance for income inequality: Cross-national and experimental evidence. Perspectives on Psychological Science, 11(3), 373-380. https://doi.org/10.1177/1745691616635596

Shaw, J. D. (2014). Pay dispersion. Annual Review of Organizational Psychology and Organizational Behavior, 1(1), 521-544.

Sheehy-Skeffington, J. (2016). Human nature in society. British Academy Review, 28 (Summer 2016).

Sherman, R. (2017). Uneasy street. Princeton University Press.

Sidanius, J., \& Pratto, F. (1999). Social dominance. Cambridge.

Simon, H. A. (1997). Models of bounded rationality: Empirically grounded economic reason (Vol. 3). MIT Press.

Son Hing, L. S., Wilson, A. E., Gourevitch, P., English, J., \& Sin, P. (2019). Failure to respond to rising income inequality: Processes that legitimize growing disparities. Daedalus, 148(3), 105-135. 
Soyer, E., \& Hogarth, R. M. (2012). The illusion of predictability: How regression statistics mislead experts. International Journal of Forecasting, 28(3), 695-711.

Stephens, N. M., Fryberg, S. A., \& Markus, H. R. (2011). When choice does not equal freedom: A sociocultural analysis of agency in working-class American contexts. Social Psychological and Personality Science, 2(1), 33-41.

Stephens, N. M., Markus, H. R., \& Phillips, L. T. (2014). Social class culture cycles: How three gateway contexts shape selves and fuel inequality. Annual Review of Psychology, 65, 611-634.

Swencionis, J. K., \& Fiske, S. T. (2018). Cross-status interactions: Concerns and consequences. Social Cognition, 36(1), 78-105. https://doi.org/10.1521/soco.2018.36.1.78

Tajfel, H. \& Turner, J. C. (1979). An integrative theory of intergroup conflict. In M. J. Hatch \& M. Schultz (Eds.), Organizational identity: A reader (pp. 56-65), Oxford University Press.

Thaler, R. H. (2000). From homo economicus to homo sapiens. Journal of Economic Perspectives, 14(1), 133-141. https://doi.org/10.1257/jep.14.1.133

Tiedens, L. Z., \& Fragale, A. R. (2003). Power moves: Complementarity in dominant and submissive nonverbal behavior. Journal of Personality and Social Psychology, 84(3), 558-568. https://doi.org/10.1037/0022-3514.84.3.558

Townsend, S. S., Major, B., Sawyer, P. J., \& Mendes, W. B. (2010). Can the absence of prejudice be more threatening than its presence? It depends on one's worldview. Journal of Personality and Social Psychology, 99(6), 933.

Trevor, C. O., Reilly, G., \& Gerhart, B. (2012). Reconsidering pay dispersion's effect on the performance of interdependent work: Reconciling sorting and pay inequality. Academy of Management Journal, 55(3), 585-610.

Trump, K.-S. (2020). When and why is economic inequality seen as fair. Current Opinion in Behavioral Sciences, 34, 46-51. https://doi.org/10.1016/j.cobeha.2019.12.001

Tversky, A., \& Kahneman, D. (1971). Belief in the law of small numbers. Psychological Bulletin, 76(2), 105.

Tversky, A., \& Kahneman, D. (1973). Availability: A heuristic for judging frequency and probability. Cognitive Psychology, 5(2), 207-232.

Tversky, A., \& Kahneman, D. (1974). Judgment under uncertainty: Heuristics and biases. Science, 185(4157), 1124-1131.

Tyler, T. (2011). Procedural justice shapes evaluations of income inequality: Commentary on Norton and Ariely (2011). Perspectives on Psychological Science, 6(1), 15-16.

Unzueta, M. M., \& Lowery, B. S. (2008). Defining racism safely: The role of self-image maintenance on white Americans' conceptions of racism. Journal of Experimental Social Psychology, 44(6), 1491-1497. https://doi.org/10.1016/j.jesp.2008.07.011

Van den Bos, K. (2009). Making sense of life: The existential self trying to deal with personal uncertainty. Psychological Inquiry, 20(4), 197-217.

Vollhardt, J. (2020). The social psychology of collective victimhood. Oxford University Press, USA.

Walasek, L., \& Brown, G. D. A. (2015). Income inequality and status seeking: Searching for positional goods in unequal U.S. states. Psychological Science, 26(4), 527-533. https://doi.org/10.1177/0956797614567511

Waldfogel, H. B., Sheehy-Skeffington, J., Hauser, O. P., Ho, A. K., \& Kteily, N. S. (2021). Ideology selectively shapes attention to inequality. Proceedings of the National Academy of Sciences, 118(14).

Wang, Q., Phillips, N. E., Small, M. L., \& Sampson, R. J. (2018). Urban mobility and neighborhood isolation in America's 50 largest cities. Proceedings of the National 
Academy of Sciences, 115(30), 7735-7740.

Weick, K. E. (1995). Sensemaking in organizations (Vol. 3). SAGE.

Wertheimer, M. (1938). Laws of organization in perceptual forms. In W. D. Ellis (Ed.), A source book of Gestalt psychology (pp. 71-88). Kegan Paul, Trench, Trubner \& Company. https://doi.org/10.1037/11496-005

Wilkins, C. L., Wellman, J. D., Babbitt, L. G., Toosi, N. R., \& Schad, K. D. (2015). You can win but I can't lose: Bias against high-status groups increases their zero-sum beliefs about discrimination. Journal of Experimental Social Psychology, 57, 1-14.

Wilson, A. E., \& Ross, M. (2000). The frequency of temporal-self and social comparisons in people's personal appraisals. Journal of Personality and Social Psychology, 78(5), 928.

Wiwad, D., Mercier, B., Piff, P. K., Shariff, A., \& Aknin, L. B. (2021). Recognizing the impact of COVID-19 on the poor alters attitudes towards poverty and inequality. Journal of Experimental Social Psychology, 93, 104083.

Xu, P., \& Garand, J. C. (2010). Economic context and Americans' perceptions of income inequality: Economic context and perceptions of income inequality. Social Science Quarterly, 91(5), 1220-1241. https://doi.org/10.1111/j.1540-6237.2010.00729.x

Yamanashi Leib, A., Chang, K., Xia, Y., Peng, A., \& Whitney, D. (2020). Fleeting impressions of economic value via summary statistical representations. Journal of Experimental Psychology: General.

Young, I. F., \& Sullivan, D. (2016). Competitive victimhood: A review of the theoretical and empirical literature. Current Opinion in Psychology, 11, 30-34.

Yu, S., \& Kilduff, G. J. (2020). Knowing where others stand: Accuracy and performance effects of individuals' perceived status hierarchies. Journal of Personality and Social Psychology, 119(1), 159.

Zitek, E. M., \& Phillips, L. T. (2020). Ease and control: The cognitive benefits of hierarchy. Current Opinion in Psychology, 33, 131-135. https://doi.org/10.1016/j.copsyc.2019.07.015 